\title{
A ROBUST DLQG CONTROLLER FOR DAMPING OF SUB - SYNCHRONOUS OSCILLATIONS IN A SERIES COMPENSATED POWER SYSTEM
}

\author{
K.C. Sindhu Thampatty ${ }^{1}$, P. C. Reghu Raj ${ }^{2}$ \\ ${ }^{1}$ Associate Professor, Dept. of Electrical and Electronics Engg, Amrita Viswa Vidyapeetham, Coimbatore, \\ Tamilnadu, \\ ${ }^{2}$ Prof \& Head, Department of Computer Science and Engineering, Govt. Engineering College, \\ Sreekrishnapuram, Palakkad, Kerala,kc_sindhu@yahoo.com pcreghu@gmail.com
}

\begin{abstract}
This paper investigates the use of Discrete Linear Quadratic Gaussian (DLQG) Compensator to damp sub synchronous oscillations in a Thyrisor Controlled Series Capacitor (TCSC) compensated power system. The study is conducted on IEEE First Benchmark Model (FBM) in which, TCSC is modelled as a discrete linear time-invariant modular unit in the synchronously rotating DQ reference frame. This modular TCSC is then integrated with the Linear Time Invariant (LTI) model of the rest of the system. The design of $D L Q G$ includes the design of a Kalman filter for full state estimation and a full state feedback for control. Since the order of the controller is as large as the order of the system considered here(27 states), the practical implementation of the controller is difficult. Hence by using Hankels norm approximation technique, the order of the controller is reduced from 27 to 15 without losing the significant system dynamics. The eigen analysis of the system shows that the use of DLQG can damp torsional oscillations as well as the swing mode oscillations simultaneously, which is practically difficult for a conventional sub-synchronous damping controller. The performance of the system with DLQG is appreciable for all operating conditions and it shows the robustness of the controller.
\end{abstract}

Index Terms: Sub-Synchronous Resonance (SSR), Torsional Oscillations, Thyristor Controlled Series Capacitor (TCSC), Discrete Linear Quadratic Gaussian(DLQG)Compensator, Model Order Reduction (MOR).

\section{INTRODUCTION}

Series capacitors have been used extensively as an economical means to increase load carrying capability, control load sharing among parallel lines and enhance transient stability. However, capacitors in series with transmission lines may cause subsynchronous resonance that can lead to turbine- generator shaft failure and electrical instability at oscillation frequencies lower than the normal system frequency [1]- [3].

Sub-synchronous resonance (SSR) has gained its name from the fact that the frequencies of interest happened to lie in a region below the synchronous frequency of the network. The phenomenon of SSR was brought to general attention in connection with the two damages that occurred to the turbine generator shafts at the Mohave Generating station in southern Nevada in the United States of America in December of 1970 and October of 1971. These two failures were analyzed and found that the failures occurred in the shaft section between the generator and the exciter of the main generator collector was due to torsional fatigue [4]- [6].

Torsional problems are most frequently encountered in rotor systems with long shafts and large inertias constituting a weakly damped mechanical system. The normal subsynchronous frequency range is between 10 to $50 \mathrm{~Hz}$ where as the swing mode oscillations are between $0.7 \mathrm{~Hz}$ to $2 \mathrm{~Hz}$. Therefore the simultaneous dampings of these oscillations are difficult with a conventional controller. Numerous papers are published on different approaches in sub-synchronous analysis and also the use of Flexible AC Transmission System (FACTS) devices to damp electromechanical oscillations [7]. Many methods [8]- [10] are proposed using series and shunt FACTS devices to improve the power system dynamic stability. To do the stability analysis, a perfect modelling of the power system is required. Various efforts have been made in the past few years to obtain a linearised state space models of TCSC [11], [12]. A modular model of TCSC is derived by Othman and Angquist [13], in which the TCSC model is derived independently and then interfaced with the rest of the system.

Kabiri et al. [14] developed a discrete model with higher sampling rate (six samples per cycle), which is a samplevariant model. In this work, the IEEE First Benchmark model with the series compensation partly done by TCSC and partly by fixed capacitor is considered. A discrete linear time invariant state space model of TCSC is presented based on Poincare mapping technique [15]. The model is based on six 
samples per cycle. The sample invariance of the model is achieved by a transformation of the zero sequence variables of different voltages and currents. The developed model is then integrated with the rest of the system.

In pole placement technique, all states must be controllable and measurable, otherwise the controller input generated by the controller doesnot affect all the state variables of the system. In multi input, multi output (MIMO) systems, pole placement is extremely difficult. $\mathrm{Yu}$ et.al, pole assignment method is employed to control all the SSR modes, by using state feedback [16]. But it was found that the approach is difficult to implement since most of the state variables were not measurable. The major drawback of pole placement method is that, if the design parameters or controller gain elements are not having enough parameters, the best possible pole allocation is not possible. Moreover the control is based on measured state variables, some state variables measurement are so noisy which can result in unsuccessful pole placement. In output feedback control scheme, some signals required for the control were difficult to measure The system we considered in this study is a multi output system having 27 states. These states are not fully controllable and observable and hence the pole placement method is not possible. Discrete time designs are important because most controllers are implemented using digital controllers. With most of the conventional controllers simultaneous damping of swing mode and torsional mode frequencies are difficult. The system we considered in this study is a discrete model of IEEE FBM which has five torsional modes. Hence our keen interest was to design a discrete controller for our discrete system. The discrete LQG approach is based on the optimal estimation and optimal control of the discrete states. The DLQG technique nearly eliminates all the trial and error method of a conventional pole placement design. This discrete design can handle low sampling rate(6 samples per cycle) associated with the system.

Hence our interest in this work is to design a controller to damp all these frequencies simultaneously. A Discrete Linear Quadratic Gaussian (DLQG) compensator is such an optimal controller with the objective of reducing a quadratic cost function of the system states and control signal. In the design of DLQG, the process noise and measurement noises are considered as white Gaussian noise signals with zero mean value. Since all the system states in this model are not observable, a Kalman filter is designed to estimate all the system states. By using these estimated states an optimal regulator is designed to control the TCSC [17] - [20].

Since the order of the DLQG controller is as large as the order of the system, practical implementation is difficult. Hence by using standard model order reduction techniques [21], [22], the order of the controller is reduced. Four different techniques are tried in this work to reduce the order of the controller namely, balanced realisation technique, optimal Hankel norm approximation technique, truncated balanced realisation and truncated residualisation technique [23]. By comparing the performance of these four methods, it has been observed that the Hankel norm approximation method of reduction gives better result. Hence in this study, the original system of 27 states is reduced to 15 states by Hankel norm approximation method and it is found that the reduced model retains the important characteristics of the original system and approximates its response as closely as possible with the original system for the same inputs. The paper is organised as follows. Section II briefly explains the sub-synchronous phenomenon. Section III explains the mathematical modelling of the TCSC and section IV explains the interconnection of this modular discrete TCSC with the rest of the power system in IEEE FBM. Section V explains the DLQG design and the model order reduction of the controller. Section VI explains the simulation results followed by the conclusion in section VII.

\section{SUB-SYNCHRONOUS RESONANCE PHENOMENON}

Sub-Synchronous Resonance (SSR) is a dynamic phenomenon in power system. The IEEE definition for SSR is "It is an electric power system condition where the electric network exchanges energy with a turbine generator at one or more of the natural frequencies of the combined system below the synchronous frequency" [3]. In a series compensated network shown in Fig.1, currents at resonance frequency fer will flow for a small electrical disturbance, where fer is given by :

$$
f_{e r}=\sqrt{\frac{X_{c}}{X_{t o t}=X_{t}+X_{l}+X_{s y s}}}
$$

Where $\mathrm{Xc}$ is the effective series capacitive reactance and $\mathrm{Xl}$ is the effective inductive reactance of the system

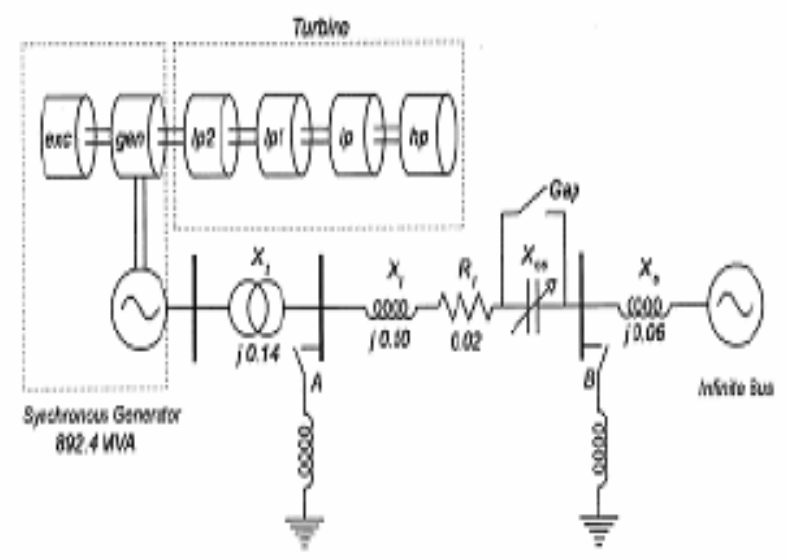

Fig.1. IEEE First Benchmark model for SSR studies

These currents appearing at the generator armature will produce a rotating magnetic field at an angular electrical speed of !er . The armature magnetic field rotating at subsynchronous speed interacts with the rotor normal dc magnetic 
field rotating at synchronous speed and develops an electromagnetic torque. The in phase component (in phase with speed ) of this torque is responsible for the sustained oscillations in the system. Torsional interaction occurs in the system, when the subsynchronous torque frequency f0 - fer is close to one of the torsional mode frequencies fn. If the damping torque component of the sub-synchronous torque equals or exceeds the inherent damping torque of the rotating system, the corresponding torsional modes will be unstable. If the generator torsional mode frequencies are different from the subsynchronous frequency, then the torsional interaction taking place in the system is very less. Since the rotor circuits are faster, the rotor resistance viewed from the armature terminal is negative. When this negative resistance exceeds the sum of the armature and network resistances, the electrical system is selfexcited [17], [18]. This effect is called Induction generator (IG) effect. This self-excitation can produce excessive voltages and currents.

When the electrical resonant frequency is near to the complement of a torsional resonant frequency of the turbinegenerator shaft system, the torsional interaction takes place. Under this condition, a small voltage induced in the armature by rotor oscillation can result in a large subsynchronous current. When the torque produced by this current is larger than that resulting from the mechanical damping torque of the system, the coupled electromechanical system will experience growing oscillations, which is called the Torsional Interaction (TI). Problem of TI is more severe than that due to IG effect.

\section{LINEAR TIME INVARIANT DISCRETE}

\section{MODEL OF TCSC}

In this section a sample invariant discrete model of TCSC [15] is presented. The main circuit of TCSC includes a capacitor, inductor and antiparallel switching thyristors. The operation of TCSC is periodic, where one of the thyristor conducts during a portion of the half cycle. The duration and timing of the conduction is based on triggering logic and is controlled by the current synchronised signals generated by PLL. Certain assumptions are made in the development of discrete model. The assumptions are:

1) The thyristors are assumed to be ideal.

2) TCSC is operated in capacitive mode only and the conduction angle of thyristors are limited to 60 electrical degrees which is the common operating range of TCSC.

3) The six sampling instants in a cycle are fixed in time and are chosen such that the conduction period of intervals are as shown in Fig 2.

4) The line current in DQO reference frame varies linearlyduring the sampling interval. i.e,

$$
i_{D Q 0}(t)=i_{D Q 0}\left(t_{0}\right)+\left(i_{D Q 0}\left(t_{1}\right)-i_{D Q 0}\left(t_{0}\right)\right) \frac{\left(t-t_{0}\right)}{h}
$$

where

$$
h=\frac{\pi}{3 * \omega_{0}}=t_{1}-t_{0}
$$

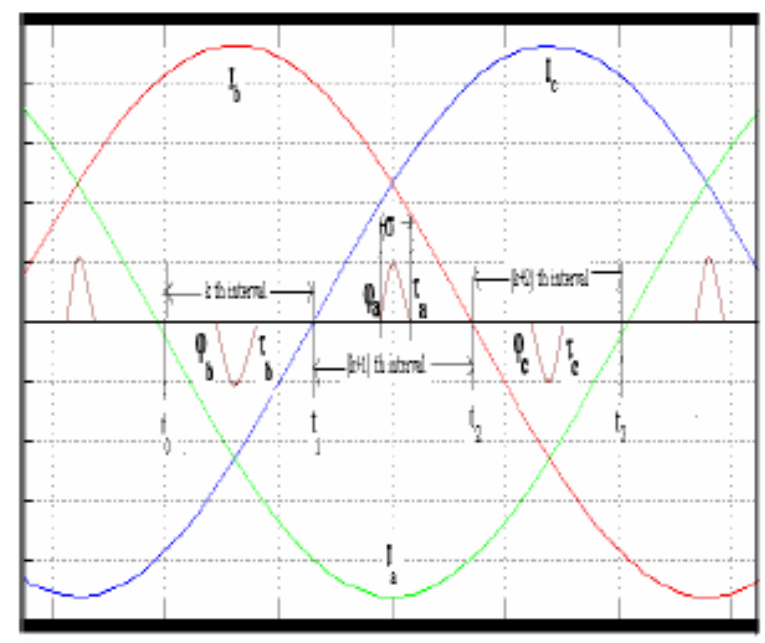

Fig.2. Timing diagram of thyristor triggering of TCSC

The thyristor turn on instant is $\phi \mathrm{a}$ and turn off instant is Ta in phase a as shown in Fig.2. Similarly the turn on and turn off instants in phase $\mathrm{b}$ and $\mathrm{c}$ can be written as $\phi \mathrm{b}, \mathrm{Tb}$ and $\phi \mathrm{c}, \mathrm{Tc}$ respectively. The conversion used to transfer three phase abc variables to DQO is given by:

$$
\left[\begin{array}{c}
f_{a} \\
f_{b} \\
f_{c}
\end{array}\right]=T\left[\begin{array}{c}
f_{D} \\
f_{Q} \\
f_{0}
\end{array}\right]
$$

where $\mathrm{T}$ is the transformation matrix given by:

$$
T=\sqrt{2 / 3}\left[\begin{array}{rrr}
\cos \omega_{0} t & \sin \omega_{0} t & \sqrt{1 / 2} \\
\cos \left(\omega_{0} t-2 \pi / 3\right) & \sin \left(\omega_{0} t-2 \pi / 3\right) & \sqrt{1 / 2} \\
\cos \left(\omega_{0} t+2 \pi / 3\right) & \sin \left(\omega_{0} t+2 \pi / 3\right) & \sqrt{1 / 2}
\end{array}\right]
$$

The conduction period of the thyristor in any one phase is shown in Fig.2. During the conduction interval of the thyristor, the TCSC is modeled as a parallel LC circuit and the corresponding differential equation in dq0 reference frame for phase a can be written as Eqn.6 and 7:

$$
\begin{gathered}
\frac{d V_{a}}{d t}=\frac{1}{C} \sqrt{\frac{2}{3}}\left[i_{D} \cos \left(\omega_{0} t\right)+i_{Q} \sin \left(\omega_{0} t\right)+\frac{i_{0}}{\sqrt{2}}\right]-\frac{i_{T a}}{C} \\
\frac{d i_{T a}}{d t}=\frac{v_{a}}{L}
\end{gathered}
$$


When the thyristors are turned off, the inductor currents are zero and hence TCSC is modeled as a simple series capacitor circuit. Then the corresponding voltage equation for phase a can be written as:

$$
\frac{d V_{a}}{d t}=\frac{1}{C} \sqrt{\frac{2}{3}}\left[i_{D} \cos \left(\omega_{0} t\right)+i_{Q} \sin \left(\omega_{0} t\right)+\frac{i_{0}}{\sqrt{2}}\right]
$$

The state space representation of phase a can be represented as:

$$
\dot{x_{a}}=A x_{a}+B_{a} I_{d q 0}
$$

Where

$$
\begin{aligned}
& x_{a}=\left[\begin{array}{c}
V_{a} \\
I_{T a}
\end{array}\right] \\
& A=\left[\begin{array}{rr}
0 & -1 / C \\
1 / L & 0
\end{array}\right] \\
& B_{a}=\sqrt{\frac{2}{3}}\left[\begin{array}{rrr}
\cos \omega_{0} t / C & \sin \omega_{0} t / C & \sqrt{1 / C \sqrt{2}} \\
0 & 0 & 0
\end{array}\right] \\
& I_{d q 0}=\left[\begin{array}{c}
I_{d} \\
I_{q} \\
I_{0}
\end{array}\right] \\
& \dot{y_{a}}=P B_{a} I_{d q 0}
\end{aligned}
$$

Where $P=\left[\begin{array}{ll}1 & 0\end{array}\right]$ and ya $=$ Va. Similar equations can be written for phases $b$ and $c$ with 1200 and 2400 phase shift.

$$
\dot{x_{b}}=A x_{b}+B_{b} I_{d q 0}
$$

where

$$
\begin{aligned}
& x_{b}=\left[\begin{array}{c}
V_{b} \\
I_{T b}
\end{array}\right] \\
& B_{b}=\sqrt{\frac{2}{3}}\left[\begin{array}{rrr}
\cos \left(\omega_{0} t-\frac{2 \pi}{3}\right) / C & \sin \left(\omega_{0} t-\frac{2 \pi}{3}\right) / C & \sqrt{1 / C \sqrt{2}} \\
0 & 0 & 0
\end{array}\right] \\
& \dot{x_{c}}=A x_{c}+B_{c} I_{d q 0} \\
& x_{c}=\left[\begin{array}{r}
V_{c} \\
I_{T c}
\end{array}\right] \\
& B_{c}= \\
& \sqrt{\frac{2}{3}}\left[\begin{array}{rrr}
\cos \left(\omega_{0} t+\frac{2 \pi}{3}\right) / C & \sin \left(\omega_{0} t+\frac{2 \pi}{3}\right) / C & \sqrt{1 / C \sqrt{2}} \\
0 & 0 & 0
\end{array}\right]
\end{aligned}
$$

To derive TCSC model in state space form, the voltage equations in phases $a, b$ and $c$ in $(k+1)$ th instant can be represented as functions of phases voltages and phase currents in kth instant and phase currents in $(k+1)$ th instants as shown in Eqn. 13.

$$
\begin{aligned}
& {\left[\begin{array}{c}
\Delta V_{a}(k+1) \\
\Delta V_{b}(k+1) \\
\Delta V_{c}(k+1)
\end{array}\right]=} F_{k}^{\prime}\left[\begin{array}{l}
\Delta V_{a}(k) \\
\Delta V_{b}(k) \\
\Delta V_{c}(k)
\end{array}\right]+G_{1 k}^{\prime}\left[\begin{array}{c}
\Delta I_{a}(k) \\
\Delta I_{b}(k) \\
\Delta I_{c}(k)
\end{array}\right]+ \\
& G_{2 k}^{\prime}\left[\begin{array}{l}
\Delta I_{a}(k+1) \\
\Delta I_{b}(k+1) \\
\Delta I_{c}(k+1)
\end{array}\right]+H_{k}^{\prime} \Delta \phi+J_{k}^{\prime} \Delta \tau(13) w
\end{aligned}
$$

where $F_{k}^{\prime}$ and $G_{k}^{\prime}$ represents the effect of different phase voltages and currents in the previous sample on the present sample. The coefficient matrices of Eqn. (13) can be calculated as:

$$
\begin{gathered}
F_{k}^{\prime}=\left[\begin{array}{rrr}
f_{a} & 0 & 0 \\
0 & f_{b} & 0 \\
0 & 0 & f_{c}
\end{array}\right] \\
H_{k}^{\prime}=\left[\begin{array}{rrr}
h_{a} & 0 & 0 \\
0 & h_{b} & 0 \\
0 & 0 & h_{c}
\end{array}\right] \\
J_{k}^{\prime}=\left[\begin{array}{rrr}
J_{a} & 0 & 0 \\
0 & J_{b} & 0 \\
0 & 0 & J_{c}
\end{array}\right] \\
G_{1 k}^{\prime}=\left[\begin{array}{c}
g_{1 a} \\
g_{1 b} \\
g_{1 c}
\end{array}\right] \\
G_{2 k}^{\prime}=\left[\begin{array}{c}
g_{2 a} \\
g_{2 b} \\
g_{2 c}
\end{array}\right]
\end{gathered}
$$

where

$$
\begin{aligned}
& f=\cos \omega_{n} \sigma, \omega_{n}=\sqrt{\frac{1}{L C}}, \sigma=\text { conduction-angle }=\tau_{b}-\phi_{b} \\
& h_{b}=\omega_{n} \sin \left(\omega_{n} \sigma\right) V_{b}\left(\phi_{b}\right), J_{b}=0
\end{aligned}
$$

$\Delta \phi_{b}$ and $\Delta \tau_{b}$ are the change in thyristor turn on and turn off instants respectively in $\mathrm{b}$ phase. From the derivation of $\mathrm{F}$, $\mathrm{H}, \mathrm{J}$ and $\mathrm{G}$ matrices [15], it is found that the variation in capacitor voltage in any phase is independent of the turn off time of the respective thyristor. In this model formulation, we have considered that the change in current during a sampling interval is a function of time and it is linearly varying during any sampling interval. This change in current can be written as: 


$$
\Delta I_{d q 0}\left(t_{1}\right)=\Delta I_{d q 0}\left(t_{0}\right)+\frac{\left(\Delta I_{d q 0}\left(t_{1}\right)-\Delta I_{d q 0}\left(t_{0}\right)\right)}{\left(t_{1}-t_{0}\right)}\left(t_{1}-t_{0}\right)
$$

The matrix equation of discrete LTI TCSC model in DQ0 reference frame after the transformation is given by:

$$
\begin{gathered}
{\left[\begin{array}{c}
\Delta V_{D}(k+1) \\
\Delta V_{Q}(k+1) \\
\Delta V_{0}(k+1)
\end{array}\right]=F_{k}\left[\begin{array}{c}
\Delta V_{D}(k) \\
\Delta V_{Q}(k) \\
\Delta V_{0}(k)
\end{array}\right]+G_{1 k}\left[\begin{array}{c}
\Delta I_{D}(k) \\
\Delta I_{Q}(k) \\
\Delta I_{0}(k)
\end{array}\right]+} \\
G_{2 k}\left[\begin{array}{c}
\Delta I_{D}(k+1) \\
\Delta I_{Q}(k+1) \\
\Delta I_{0}(k+1)
\end{array}\right]+H_{k} \Delta \phi(k)(20)
\end{gathered}
$$

Where $\left.F_{k}=T^{-1}\left(t_{1}\right) F_{k}^{\prime} T\left(t_{0}\right), G_{1 k}=T^{-1}\left(t_{1}\right)\right) G_{1 k}^{\prime}$

$$
\left.G_{2 k}=T^{-1}\left(t_{1}\right)\right) G_{2 k}^{\prime}, H_{k}=T^{-1}\left(t_{1}\right) H_{k}^{\prime}
$$

The time varying transformation matrix $\mathrm{T}$ is evaluated (5) at instants $\mathrm{t} 0$ as $\mathrm{T}(\mathrm{t} 0)$ and $\mathrm{t} 1$ as $\mathrm{T}(\mathrm{t} 1)$. Similar equations can be written for other phases also. It is observed that the state space equations are not sample invariant. i.e., for any sample, the matrix at kth interval and $(k+2)$ thinterval are same. It is also observed that the sign of all coupling terms between zero sequence variables and $\mathrm{DQ}$ variables in the $\mathrm{F}, \mathrm{G}$ matrices and the last row of $\mathrm{H}$ matrix alternates at consecutive sampling instants. In this discrete model of TCSC, to make the model sample invariant, a transformation is applied to the zero sequence variables as given in equation:

$$
\begin{gathered}
I_{0}(k)=(-1)^{k} I_{z}(k) \\
V_{0}(k)=(-1)^{k} V_{z}(k)
\end{gathered}
$$

Where $\mathrm{k}$ indicates any sample. After the above transformation, the sample invariant TCSC equations can be obtained as :

$$
\begin{gathered}
{\left[\begin{array}{c}
\Delta V_{D}(k+1) \\
\Delta V_{Q}(k+1) \\
\Delta V_{z}(k+1)
\end{array}\right]=\mathbf{F}\left[\begin{array}{c}
\Delta V_{D}(k) \\
\Delta V_{Q}(k) \\
\Delta V_{z}(k)
\end{array}\right]+\mathbf{G}_{1}\left[\begin{array}{c}
\Delta I_{D}(k) \\
\Delta I_{Q}(k) \\
\Delta I_{z}(k)
\end{array}\right]+} \\
\mathbf{G}_{2}\left[\begin{array}{c}
\Delta I_{D}(k+1) \\
\Delta I_{Q}(k+1) \\
\Delta I_{0}(k+1)
\end{array}\right]+\mathbf{H} \Delta \phi(k)(23
\end{gathered}
$$

It is found that the sample invariant transformation is consistent and the transformed zero sequence components retain their coupling to D and Q components of currents and voltages. When the developed TCSC model is interfaced with the rest of the power system, the discredited zero sequence variables of the system is also to be transformed (Eqn. 21 and 22) to obtain the time invariance.

\section{MODEL OF THE REST OF THE SYSTEM}

The rest of the system consists of turbine-generator system, transmission line, PLL and TCSC controller. The schematic diagram of the full system with TCSC is shown in Fig.3. TCSC voltage VDQ0 is the input for the rest of the system.

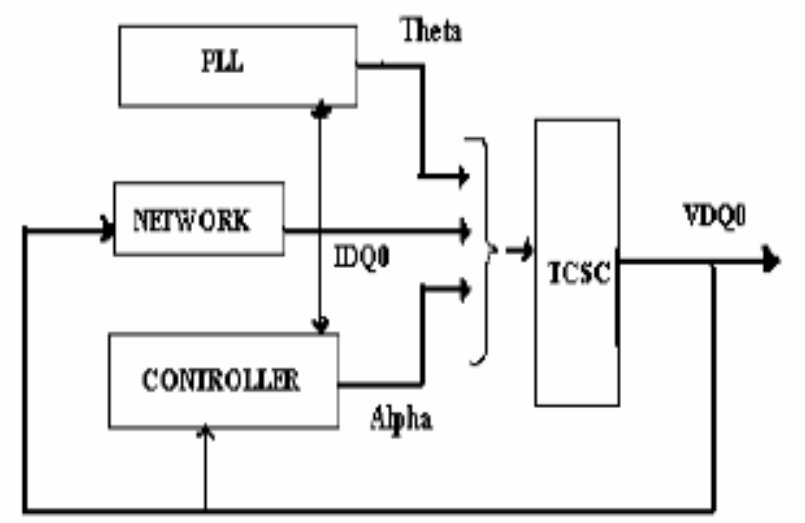

Fig.3. Block diagram representation of a controller connected to TCSC

\section{A. Turbine -Generator model}

The system considered here is the IEEE First Benchmark model which has totally six masses including the generator and exciter. Synchronous machine considered in this study is 2.2 models where the first digit refers to the number of windings in the q-axis [IEEE (1986)]. In 2.2 model, three phase armature windings ( $a, b$ and $c$ ) on the stator and four windings on the rotor including the field winding ' $f$ ' are placed. The amortisser (or damper) circuits in the salient pole machine or the eddy current effects in the rotor are represented by a set of coils with constant parameters. Three damper windings, ' $h$ ' in the $d$ axis and $\mathrm{g}, \mathrm{k}$ in the $\mathrm{q}$ axis are placed. Following assumptions are made in the derivation of the basic electrical equations of the machine:

- The mmf in the air gap is distributed sinusoidally and the harmonics are neglected.

- Saliency is restricted to the rotor. Effect of slots in the stator is neglected.

- Magnetic saturation and hysteresis are ignored.

The mechanical system consisting of rotors of generator exciter, turbines and shafts can be viewed as a mass springdamper system. Assumptions made in the modeling of mechanical system are:

- The system masses are considered as lumped masses.

- Slip at the operating point is zero. 
Assuming the fluxes linking with different rotor coils are free of harmonics, the time invariant linearised model about an equilibrium point can be written as :

$$
\Delta x_{G}=A_{G} \Delta x_{G}+B_{G} \Delta U_{G}
$$

$$
\Delta y_{G}=C_{G} \Delta x_{G}
$$

where $\Delta x_{G}^{T}=\left[x_{e}^{T} x_{m}^{T}\right], x_{e}^{T}, x_{m}^{T}$ represents the electrical and mechanical state variables. Totally there are six electrical state variables and twelve mechanical state variables in the system considered in this study. The control input $\Delta U_{G}$ contains the $\mathrm{D}$ and $\mathrm{Q}$ components of generator terminal voltages given by:

$$
\begin{gathered}
\Delta U_{G}^{T}=\left[\Delta V_{D} \Delta V_{Q}\right] \\
\Delta y_{G}^{T}=\left[\Delta I_{D} \Delta I_{Q}\right]
\end{gathered}
$$

where $\Delta I_{D}$ and $\Delta I_{Q}$ represents the $\mathrm{D}$ and $\mathrm{Q}$ components of generator current injection.

\section{B. Electrical network model}

Electrical AC network consists of transformers, transmission lines with fixed series compensation. Transformers are modeled by representing its equivalent leakage reactance $\mathrm{Xt}$ and the transmission lines are represented by its equivalent impedance as shown in Fig. 1. The state space representation of the electrical network is represented as:

$$
\begin{gathered}
\Delta \dot{x_{N}}=A_{N} \Delta x_{N}+B_{N} \Delta V_{D Q 0} \\
\Delta I_{D Q 0}=C_{N} \Delta x_{N}+D_{N} \Delta V_{D Q 0}
\end{gathered}
$$

$$
\Delta V_{D Q 0}=\left[\begin{array}{c}
\Delta V_{D} \\
\Delta V_{Q} \\
\Delta V_{0}
\end{array}\right] \text { and } \Delta I_{D Q 0}=\left[\begin{array}{c}
\Delta I_{D} \\
\Delta I_{Q} \\
\Delta I_{0}
\end{array}\right]
$$

\section{Current synchronised PLL}

A current synchronised PLL is designed for the setting of firing scheme for TCSC. The set time for firing of the thyristor starts from the previous zero crossing of the line current. The timing signal generated by PLL in steady state et is shown in Fig.4.

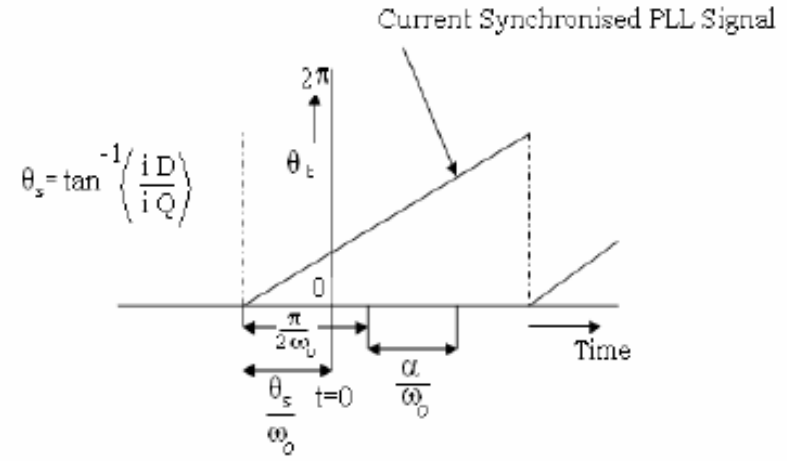

Fig.4. Operation of PLL

The state space equation of PLL can be expressed as :

$$
\begin{gathered}
\Delta x_{P L L}=A_{P L L} \Delta x_{P L L}+B_{P L L} \Delta I_{D Q 0} \\
\Delta \theta_{t}=C_{P L L} \Delta x_{P L L}
\end{gathered}
$$

\section{The conventional TCSC controller model}

The conventional TCSC controller controls the firing angle $\alpha$ of the thyristor to meet the required objective. The conventional controller consists of a gain block, a signal washout block and a phase compensation block as shown in Fig.5. The phase compensation block provides the appropriate phase lead characteristics to compensate for the phase lag between input and output signals. The signal washout block serves as a high pass filter which allows signals associated with oscillations in input signal to pass unchanged.

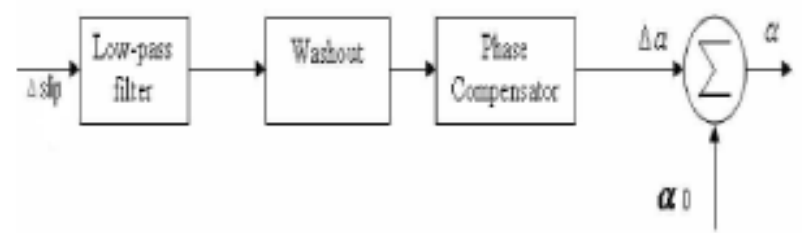

Fig. 5. Structure of a conventional controller

The general form of controller equation is given by:

$$
\begin{gathered}
\Delta \dot{x_{C}}=A_{C} \Delta x_{C}+B_{C}\left[\begin{array}{r}
\Delta x_{N} \\
\Delta V_{D Q 0}
\end{array}\right] \\
\Delta \alpha=C_{C} \Delta x_{C}+D_{C}\left[\begin{array}{r}
\Delta x_{N} \\
\Delta V_{D Q 0}
\end{array}\right]
\end{gathered}
$$




\section{E. The interfaced discrete-time model of the system}

Combining the discretised equations of generator-turbine, transmission network and the PLL with the discrete model of TCSC, the overall system equation can be written as:

$$
\Delta x_{\text {sys }}(k+1)=A_{\text {sys }} \Delta x_{\text {sys }}(k)
$$

where $\Delta x_{\text {sys }}$ represent the discrete state variables of the full system, which is a vector of 27 states in this case. The discrete time system eigen-values $\lambda_{d}$ of the system are converted to equivalent continuous-time eigen-values $\lambda_{c}$ by:

$$
\lambda_{c}=\frac{\log \left(\lambda_{d}\right)}{h}
$$

Where $\mathrm{h}$ is the sampling time. Eigen values of the system with the conventional controller is shown in Table 1 in which, $\mathrm{K}$ represent the gain of the conventional controller. As shown in Table 1, increased gain can stabilize the swing mode, but torsional mode 4 gets destabilised. Hence it is observed that, the simultaneous damping of all modes using the conventional controller is difficult. It may be desirable to have a separate Power Swing Damping Controller (PSDC) and subsynchronous Damping Controller (SSDC). In the next section the design of DLQG compensator is discussed for the above system which gives simultaneous damping of torsional mode as well as the swing mode oscillations. The conventional PSDC along with SSDC for damping SSR as well as swing mode oscillations can be replaced by a single robust DLQG, which also guarantees the system stabilisation also.

\section{ROBUST CONTROL DESIGN USING DISCRETE LINEAR QUADRATIC GAUSSIAN (DLQG) COMPENSATOR}

DLQG design is an optimal control design which produces the best possible control system for a given set of performance objectives. Usually a quadratic cost function known as performance index of the system states and control signal must be minimised by feeding back the optimal states. In most of the practical systems, all the system state variables are not available for the measurement. Hence it is necessary to use an optimal estimator for state estimation. In this work the design of DLQG involves the design of Kalman filter as an optimal estimator, and the estimated states are fed back to the system as state feedback control law.

\section{A. The design of state feedback controller}

The discrete system to be controlled is represented in the state space form as:

$$
\begin{gathered}
x(k+1)=A(k) x(k)+B(k) u(k) \\
y(k)=C(k) x(k)+D(k) u(k)
\end{gathered}
$$

where $A(k), B(k), C(k)$ are state space matrices of the system and $x(k), y(k)$ are the state and system output vector respectively. The optimal feedback law can be represented as:

$$
u(k)=-K(k) x(k)
$$

where $K(k)$ is the gain of the optimal controller. The cost function to be minimised in the controller design is given by:

$$
J(k)=\sum_{k=0 \in N}\left[x^{T}(k) Q(k) x(k)+u^{T}(k) R u(k)\right]
$$

Where $\mathrm{Q}$ is a symmetric positive semi definite state weighting matrix and $\mathrm{R}$ is a symmetric positive definite control weighting matrix. The optimisation function represents the weighted sum of energy of the states and control. The gain $\mathrm{K}$ of the optimal controller is derived from the algebraic discrete time Riccati equation given by:

$$
P=A^{T} P A+Q-A^{T} P B\left(B^{T} P B+R\right)^{-1} B^{T} P A
$$

Where $\mathrm{P}$ is the solution of the Riccati equation the optimal control can be expressed as:

$$
K=-\left(B^{T} P B+R\right)^{-1} B^{T} P A
$$

In stochastic systems, this control law guarantees to bring the system states close to zero. This is an advantage of the linear quadratic method that a stabilising controller is obtained where as in classical controls, the stabilising controller is designed separately.

\section{B. The design of Kalman filter as an optimal estimator}

The Kalman filter is an optimal state estimator for linear dynamical systems, which minimises the estimation error given as:

$$
e(k)=x(k)-\hat{x}(k)
$$

And this linear minimum mean square problem can be solved recursively. A noisy plant with the presence of modelling uncertainties called process noise and measurement noise can be modeled by passing white gaussian noise through an appropriate linear system. Such a plant can be represented in state space form as:

$$
\begin{gathered}
x(k+1)=A(k) x(k)+B(k) u(k)+F(k) v(k) \\
y(k)=C(k) x(k)+D(k) u(k)+z(k)
\end{gathered}
$$


Where $\mathrm{v}(\mathrm{k})$ is the process noise vector produced due to modeling errors and $\mathrm{z}(\mathrm{k})$ is the measurement noise vector. These noises can be assumed as uncorrelated white Gaussian zero mean stationary noises.

The optimal Kalman filter gain can be represented as:

$$
L(k)=R(k) C^{T}(k) Z^{-1}(k)
$$

Where $R(k)$ is the optimal covariance matrix satisfying the matrix Riccati equation. The dynamics of the controller can be expressed as:

$$
\begin{gathered}
\hat{x}(k+1)=A \hat{x}(k)+B u(k)+L(y-C \hat{x}(k)) \\
u=-K \hat{x}(k)
\end{gathered}
$$

where $\hat{x}$ are the estimated state variables and $L$ is the Kalman filter gain.

The system stability robustness depends on the weighting matrices Q and R. By analysing the dominant parameters that effect SSR like mechanical parameters, the weighting matrices are properly tuned assuring system stability robustness. The order of the DLQG compensator designed for a system is same as the order of the system. Hence the implementation of such a large controller is practically difficult and it is advisable to reduce the controller order. The order reduction can be done in two ways. Either the system order will be reduced and then the controller is designed for the reduced system or the controller is designed for large systems and then reduces the order of the controller.

\section{Model order reduction of DLQG}

Standard methods are available for the model order reduction of the large system like Pade's approximation, model approximation or continued fraction expansion etc. In this study, model order reduction by four different methods are tried namely, balanced realisation technique, optimal Hankel norm approximation technique, truncated balanced realisation and truncated residualisation technique. Figure 8 shows the frequency response plotted by using different techniques.

By comparing the results obtained in different methods, theresponse obtained by Hankel norm approximation technique closely matches with the original system. Hence in this work, the Hankel norm approximation technique is chosen for orderreduction and the controller order is reduced from 27 to 11. This order reduction assures the desirable performance and stability robustness of the controller. After reducing the order of the controller, the reduced controller is connected to the original system. In this work, the model order reduction is done using $\mu$ control toolbox in MATLAB.
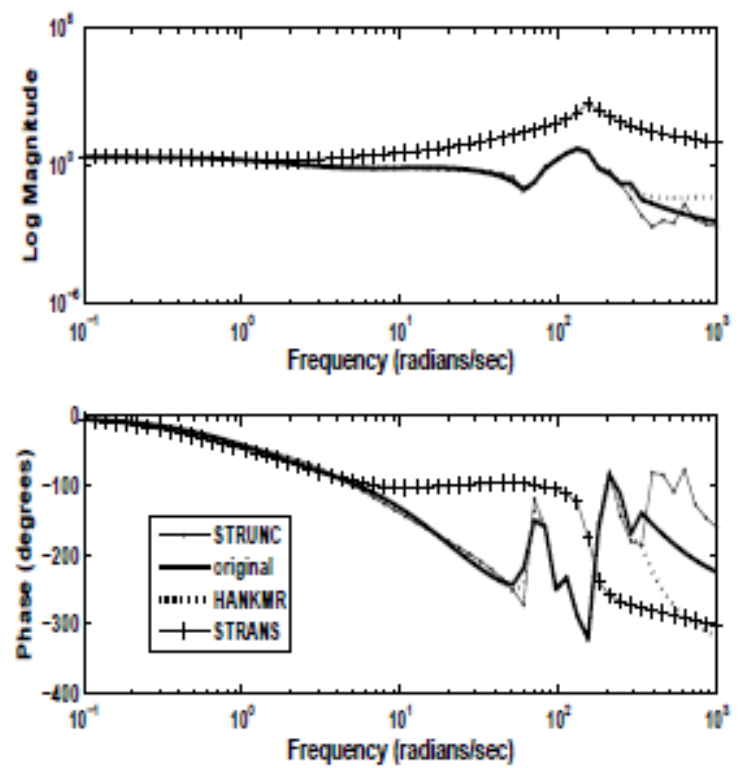

Fig.6. Comparison of different model order reduction techniques

\section{SIMULATION RESULTS}

Simulation studies are conducted on the IEEE FBM for SSR studies which is enhanced with TCSC. The system consists of 892.4 MVA synchronous generators connected to an infinite bus through a series compensated $500 \mathrm{kV}$ transmission line.

Mechanical damping of the system is assumed to be zero in the analysis in order to present the worst case damping conditions. In order to reduce the complexity, all calculations are made in p.u, taking $500 \mathrm{kV}$ as the base value. The simulation scenario is as follows. The system is operating in its steady state condition for a given operating condition. Then an impulse increase in torque for $10 \%$ is injected to the shaft section connecting the masses LPA and LPB and the simulations are carried out for different operating conditions.

The torsional mode stability has been analyzed using the eigen value technique. Results of this analysis with different firing angles of the thyristor are consolidated in Table II through Table V. It has been observed from Tables III and IV that the unstable torsional mode 4 gets stabilised by DLQG and that the damping of all other torsional modes are increased with DLQG. Damping of all the torsional modes are drastically improved with DLQG as shown in Table V for the firing angle $\alpha=170^{\circ}$. 
TABLE II

SUBSYNCHRONOUS MODES WITH DLQG (P=1P.U,V=1P.U, $\left.\alpha=155^{0}\right)$

\begin{tabular}{|l|l|l|}
\hline Without controller & With controller & comments \\
\hline $0.0 \pm 298.18 \mathrm{i}$ & $0.0 \pm 298.18 \mathrm{i}$ & Torsional mode 5 \\
$-0.05267 \pm 202.82 \mathrm{i}$ & $-3.7157 \pm 203.11 \mathrm{i}$ & Torsional mode 4 \\
$-0.17769 \pm 160.55 \mathrm{i}$ & $-4.5457 \pm 160.79 \mathrm{i}$ & Torsional mode 3 \\
$-0.035496 \pm 127.03 \mathrm{i}$ & $-0.76647 \pm 126.89 \mathrm{i}$ & Torsional mode 2 \\
$-0.32463 \pm 99.186 \mathrm{i}$ & $-6.3015 \pm 99.607 \mathrm{i}$ & Torsional mode 1 \\
$\mathbf{- 2 8 . 5 6 4} \pm \mathbf{1 6 5 . 2 1 i}$ & $\mathbf{- 3 0 . 5 3} \pm \mathbf{1 6 3 . 5 9 i}$ & Network mode \\
\hline
\end{tabular}

TABLE III

SUBSYNCHRONOUS MODES WITH DLQG $\left(\mathrm{P}=1 \mathrm{P} . \mathrm{U}, \mathrm{V}=1 \mathrm{P} . \mathrm{U}, \alpha=157.5^{\circ}\right)$

\begin{tabular}{|l|l|l|}
\hline Without controller & With controller & comments \\
\hline $0.0 \pm 298.18 \mathrm{i}$ & $0.0 \pm 298.18 \mathrm{i}$ & Torsional mode 5 \\
$\mathbf{0 . 0 1 2 5 6} \pm \mathbf{2 0 2 . 7 9 i}$ & $\mathbf{- 2 . 5 1 6 9} \pm \mathbf{2 0 3 . 0 3 i}$ & Torsional mode 4 \\
$-0.1391 \pm 160.53 \mathrm{i}$ & $-2.9511 \pm 160.5 \mathrm{i}$ & Torsional mode 3 \\
$-0.025 \pm 127 \mathrm{i}$ & $-0.48774 \pm 126.95 \mathrm{i}$ & Torsional mode 2 \\
$-0.2346 \pm 98.85 \mathrm{i}$ & $-5.0083 \pm 99.339 \mathrm{i}$ & Torsional mode 1 \\
$-\mathbf{- 1 7 . 8 7 2} \pm \mathbf{1 7 8 . 8 5 i}$ & $-\mathbf{1 8 . 0 9} \pm \mathbf{1 7 9 . 1 8 i}$ & Network mode \\
\hline
\end{tabular}

TABLE IV

SUBSYNCHRONOUS MODES WITH DLQG (P=1P.U,V $=1$ P.U, $\left.\alpha=165^{0}\right)$

\begin{tabular}{|l|l|l|}
\hline Without controller & With controller & comments \\
\hline $0.0 \pm 298.18 \mathrm{i}$ & $0.0 \pm 298.18 \mathrm{i}$ & Torsional mode 5 \\
$\mathbf{0 . 0 1 5 5 4} \pm \mathbf{2 0 2 . 8 4 i}$ & $-\mathbf{0 . 9 9 4 7} \pm \mathbf{2 0 2 . 8 7 i}$ & Torsional mode 4 \\
$-0.05815 \pm 160.4 \mathrm{i}$ & $-2.0963 \pm 160.57 \mathrm{i}$ & Torsional mode 3 \\
$-0.04754 \pm 127 \mathrm{i}$ & $-0.4107 \pm 126.96 \mathrm{i}$ & Torsional mode 2 \\
$-0.3899 \pm 98.945 \mathrm{i}$ & $-2.703 \pm 98.979 \mathrm{i}$ & Torsional mode 1 \\
$-\mathbf{1 9 . 3 2 5} \pm \mathbf{1 5 0 . 4 4 i}$ & $-\mathbf{1 9 . 6 1 5} \pm \mathbf{1 5 0 . 4 8 i}$ & Network mode \\
\hline
\end{tabular}

TABLE V

SUBSYNCHRONOUS MODES WITH DLQG $\left(\mathrm{P}=1\right.$ P.U, V $=1$ P.U, $\left.\alpha=170^{\circ}\right)$

\begin{tabular}{|l|l|l|}
\hline Without controller & With controller & comments \\
\hline $0.0 \pm 298.18 \mathrm{i}$ & $0.0 \pm 298.18 \mathrm{i}$ & Torsional mode 5 \\
$-0.0316 \pm 202.84 \mathrm{i}$ & $-2.9919 \pm 203.02 \mathrm{i}$ & Torsional mode 4 \\
$-0.13887 \pm 160.51 \mathrm{i}$ & $-4.0347 \pm 160.79 \mathrm{i}$ & Torsional mode 3 \\
$-0.0369 \pm 127.02 \mathrm{i}$ & $-0.71788 \pm 126.9 \mathrm{i}$ & Torsional mode 2 \\
$-0.34027 \pm 99.102 \mathrm{i}$ & $-5.6061 \pm 99.376 \mathrm{i}$ & Torsional mode 1 \\
$\mathbf{- 2 8 . 8 7 1} \pm \mathbf{1 5 8 . 6 5 i}$ & $\mathbf{- 2 9 . 6 3 3} \pm \mathbf{1 5 8 i}$ & Network mode \\
\hline
\end{tabular}

The pole-zero mapping of the system with and without DLQG for three different firing angles of TCSC are shown in Figures 7 through 12. From these figures, it has been observed that most of the poles on the surface of the unit circle are pushed towards the center of the circle with DLQG compensator. It has been observed that, in the case of the system with and without DLQG, zeros of the system is the same, but the locations of the poles are quite different. It can be seen that the system in open loop is unstable with poles outside the unit circle, whereas this mode becomes very well damped with DLQG. The stability of most of the torsional modes is improved with DLQG.

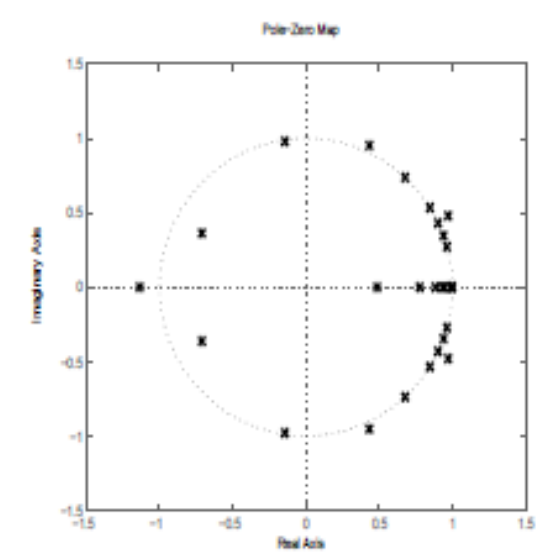

Fig. 7. PZMAP of the system $\left(\alpha=155^{\circ}\right)$ without DLQG

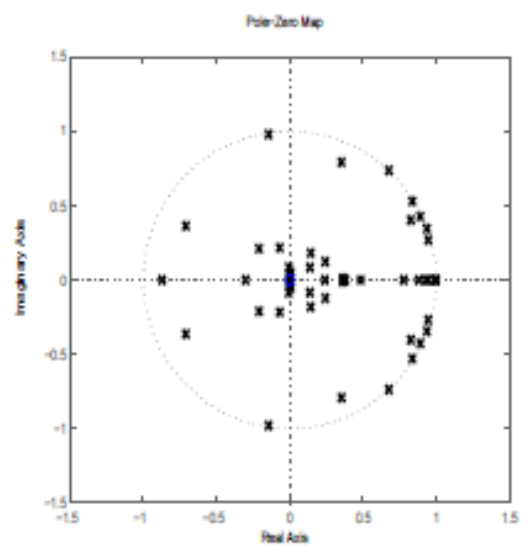

Fig. 8. PZMAP of the system $\left(\alpha=155^{\circ}\right)$ with DLQG

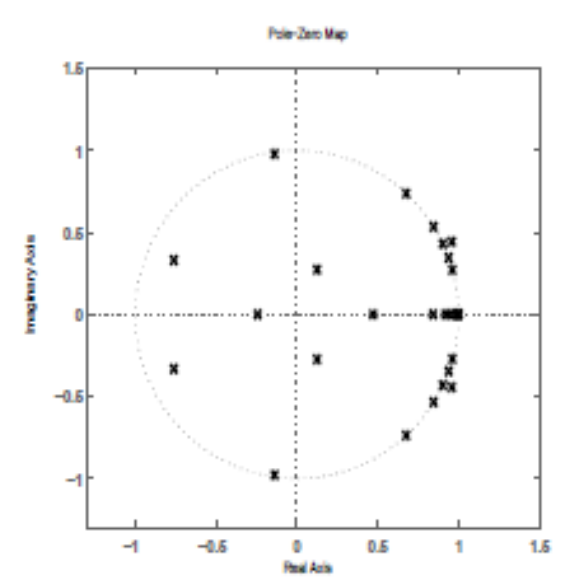

Fig. 9. PZMAP of the system $\left(\alpha=165^{0}\right)$ without DLQG 


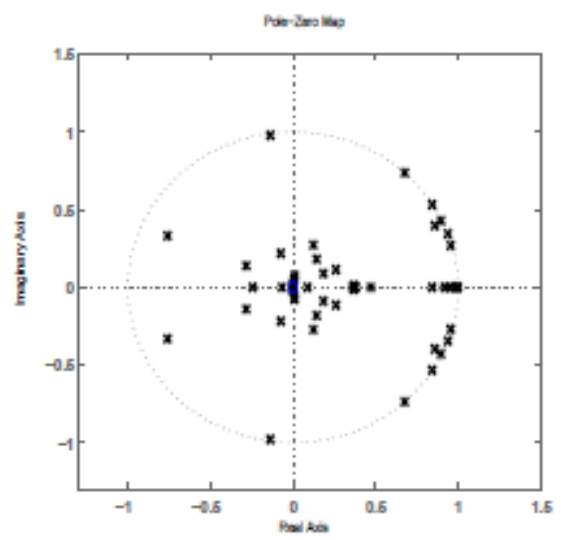

Fig. 10. PZMAP of the system $\left(\alpha=165^{0}\right)$ with DLQG

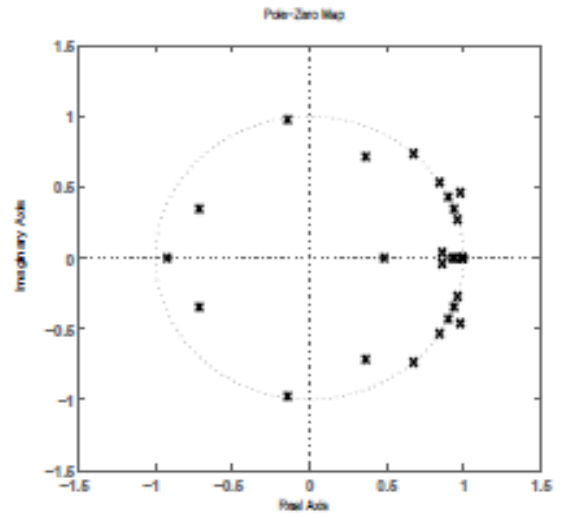

Fig. 11. PZMAP of the system $\left(\alpha=170^{0}\right)$ without DLQG

\section{ROBUSTNESS EVALUATION}

Extensive simulations have been carried out to assess the robustness of the proposed DLQG compensator for TCSC in different operating conditions. The real power is varied from 0.2 p.u to 1.2 p.u and the terminal voltage is varied between 0.5 p.u to 1 p.u. As the stability of the torsional modes varies with the mehanical parameters of the system like inertia and spring constant as shown in Fig. 13 and Fig. 14, in order to reflect the parameter uncertainties, the random errors with the variation of $10 \%$ to $70 \%$ are added to these parameters of each mechanical mass. Similarly the level of series compensation is varied from $10 \%$ to $70 \%$ by changing the firing angle. In all these cases, the DLQG is designed such that the maximum overshoot in each state variable doesnot exceed more than $3 \%$ and settling time must be less than 2 seconds after the occurence of the disturbance. The system performance has been analyzed using a reduced order controller also and it has been observed that the performance of the system with the reduced controller is matching with that of the full order controller.

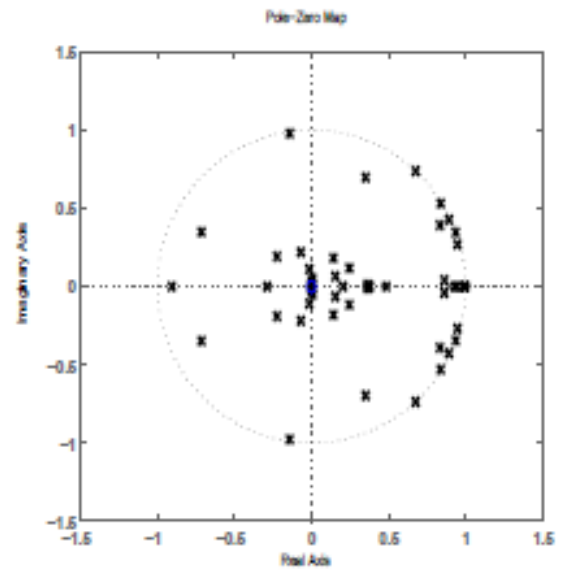

Fig. 12. PZMAP of the system $\left(\alpha=170^{0}\right)$ with DLQG

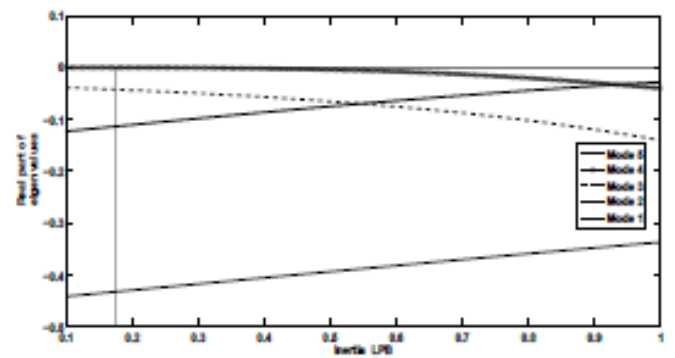

Fig. 13. Damping of torsional modes as a function of inertia of LPB

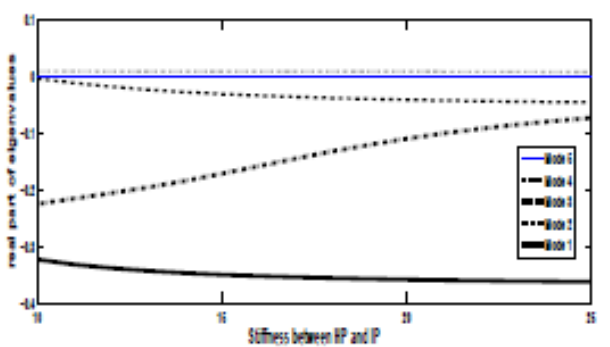

Fig. 14. Damping of torsional modes as a function of shaft stiffiness between masses HP and IP

The results of the eigen analysis conducted on the system with the conventional controller is shown in Table VI. As seen in this table, when the gain of the conventional controller increases, torsional mode 4 gets undamped even though the damping of the other modes increases. The simultaneous 
damping of all the torsional modes using the conventional controller is difficult. Hence, it is desirable to have a separate Power Swing Damping Controller (PSDC) to damp swing mode oscillation and a Subsynchronous Damping Controller (SSDC) to damp SSR oscillations. The simultaneous damping of torsional as well as the swing mode oscillations is possible with the DLQG compensator and damping of all the torsional modes are improved with DLQG compensator.

Optimal solution of the cost function and hence the simultaneous damping of the swing mode and torsional modes can be achieved by properly tuning the $\mathrm{Q}$ and $\mathrm{R}$ matrices(weighing matrices of system states and the control inputs) in the cost function.

TABLE VI

SUBSYNCHRONOUS MODES WITH CONVENTIONAL CONTROLLER(P=1P.U,V $=1$ P.U, $\left.\alpha=170^{\circ}\right)$

\begin{tabular}{|l|l|l|l}
\hline $\mathrm{K}=0$ & $\mathrm{~K}=\mathbf{7 0}$ & $\mathrm{K}=\mathbf{2 0 0}$ & comments \\
\hline $.401 \pm 9.67 \mathrm{i}$ & $.226 \pm 9.64 \mathrm{i}$ & $-0.093 \pm 9.57 \mathrm{i}$ & swing mode \\
$-0.005 \pm 99.23 \mathrm{i}$ & $-0.352 \pm 98.83 \mathrm{i}$ & $-.957 \pm 98.09 \mathrm{i}$ & Torsional mode1 \\
$0.001 \pm 127.04 \mathrm{i}$ & $-0.051 \pm 126.97 \mathrm{i}$ & $-0.136 \pm 126.86 \mathrm{i}$ & Torsional mode2 \\
$0.027 \pm 160.71 \mathrm{i}$ & $-0.464 \pm 160.2 \mathrm{i}$ & $-1.17 \pm 159.28 \mathrm{i}$ & Torsional mode3 \\
$0.642 \pm \mathbf{2 0 2 . 7 6 i}$ & $-0.615 \pm \mathbf{2 0 9 . 2 4 i}$ & $\mathbf{2 . 4 2} \pm \mathbf{2 1 7 . 7 3 i}$ & Torsional mode4 \\
$0.0 \pm 298.18 \mathrm{i}$ & $0.0 \pm 298.18 \mathrm{i}$ & $0.0 \pm 298.18 \mathrm{i}$ & Torsional mode5 \\
$-10.23 \pm 200.36 \mathrm{i}$ & $-6.53 \pm 196.61 \mathrm{i}$ & $-5.24 \pm 193.04 \mathrm{i}$ & Subs.network mi \\
\hline
\end{tabular}

TABLE VII

DAMPING OF SUBSYNCHRONOUS MODES-COMPARISON ( $\mathrm{P}=1 \mathrm{P} . \mathrm{U}, \mathrm{V}=1$ P.U, $\alpha=160^{\circ}$ )

\begin{tabular}{|l|l|l|l|}
\hline $\begin{array}{l}\text { Without con- } \\
\text { troller }\end{array}$ & $\begin{array}{l}\text { With } \\
\text { conventional } \\
\text { controller }\end{array}$ & With DLQG & comments \\
\hline $0.468 \pm 9.71 \mathrm{i}$ & $-0.23 \pm 9.66 \mathrm{i}$ & $-363.67 \pm 10.19 \mathrm{i}$ & Swing mode \\
\hline $0.022 \pm 99.18 \mathrm{i}$ & $-1.2 \pm 99.24 \mathrm{i}$ & $-3.416 \pm 98.98 \mathrm{i}$ & Torsional mode1 \\
\hline $0.003 \pm 127.031$ & $-0.147 \pm 127.05 \mathrm{i}$ & $-0.389 \pm 126.99 \mathrm{i}$ & Torsional mode2 \\
\hline $0.026 \pm 160.66 \mathrm{i}$ & $-0.83 \pm 160.921$ & $-3.219 \pm 160.36 \mathrm{i}$ & Torsional mode3 \\
\hline $0.24 \pm 203.13 \mathrm{i}$ & $-2.532 \pm 210.67 \mathrm{i}$ & $-1.377 \pm 202.88 \mathrm{i}$ & Torsional mode4 \\
\hline $0.0 \pm 298.18 \mathrm{i}$ & $0.0 \pm 298.18 \mathrm{i}$ & $-0.002 \pm 298.18 \mathrm{i}$ & Torsional mode5 \\
\hline$-14.7 \pm 217.41$ & $-8.77 \pm 208.331$ & $-14.15 \pm 167.71 \mathrm{i}$ & $\begin{array}{l}\text { Subnetwork } \\
\text { mode }\end{array}$ \\
\hline
\end{tabular}

A comparison of the stability of torsional modes, swing mode and the network mode are made with a conventional controller, DLQG compensator and without any controller as shown in Table VII and Table VIII for different thyristor triggering angles.

It has been observed that the damping of all modes is highly improved with DLQG compensator compared to a conventional controller. In order to prove the controller robustness, the system performance with the proposed controller is evaluated for various operating conditions. When a small change in the torque is applied to the shaft section between masses LPA and LPB, it produces changes in other shaft sections. Figures 15 through 17 shows the deviation of torque in different shaft section for real power $\mathrm{P}=1 \mathrm{pu}$, terminal voltage $\mathrm{V}=1 \mathrm{pu}$ and thyristor firing angle of 1650 . The torque in the shaft sections connecting the generator and the exciter is very small compared to other shaft sections as shown in Fig. 16 and its maximum value is nearly 0.03 p.u. But the oscillations persist for longer duration. The variation of torque in shaft section connecting between masses HP and IP is having minimum deviation. All these oscillations are having maximum deviations only for few cycles and after that its magnitude decreases drastically.

TABLE VIII

DAMPING OF SUBSYNCHRONOUS MODES-COMPARISON ( $\mathrm{P}=1$ P.U, $\mathrm{V}=1$ P.U, $\alpha=170^{\circ}$ )

\begin{tabular}{|l|l|l|l|}
\hline $\begin{array}{l}\text { Without con- } \\
\text { troller }\end{array}$ & $\begin{array}{l}\text { With } \\
\text { conventional } \\
\text { controller }\end{array}$ & With DLQG & comments \\
\hline $0.401 \pm 9.67 \mathrm{i}$ & $-0.093 \pm 9.57 \mathrm{i}$ & $-0.371 \pm 9.8 \mathrm{i}$ & Swing mode \\
\hline$-0.01 \pm 99.23 \mathrm{i}$ & $-.957 \pm 98.09 \mathrm{i}$ & $-5.61 \pm 99.376 \mathrm{i}$ & Torsional mode1 \\
\hline $0.001 \pm 127.04 \mathrm{i}$ & $-0.14 \pm 126.86 \mathrm{i}$ & $-0.7179 \pm 126.9 \mathrm{i}$ & Torsional mode2 \\
\hline $\begin{array}{l}0.03 \\
\pm 160.71 \mathrm{i}\end{array}$ & $-1.17 \pm 159.28 \mathrm{i}$ & $-4.04 \pm 160.79 \mathrm{i}$ & Torsional mode3 \\
\hline $0.642 \pm 202.76 \mathrm{i}$ & $2.42 \pm 217.73 \mathrm{i}$ & $-2.99 \pm 203.02 \mathrm{i}$ & Torsional mode4 \\
\hline $0.0 \pm 298.18 \mathrm{i}$ & $0.0 \pm 298.18 \mathrm{i}$ & $0.0 \pm 298.18 \mathrm{i}$ & Torsional mode5 \\
\hline$-10.23 \pm$ & $-5.24 \pm 193.04 \mathrm{i}$ & $-29.633 \pm 158 \mathrm{i}$ & $\begin{array}{l}\text { Subnetwork } \\
\text { mode }\end{array}$ \\
\hline $200.4 \mathrm{i}$ & & & \\
\hline
\end{tabular}

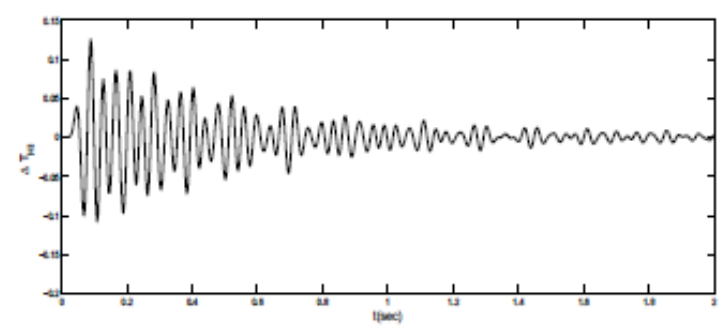

Fig. 15. Variation of Torque in shaft section between HP-IP masses $\mathrm{P}=1 \mathrm{pu}$, $\mathrm{V}=1 \mathrm{pu}, \alpha=165^{\circ}$ 

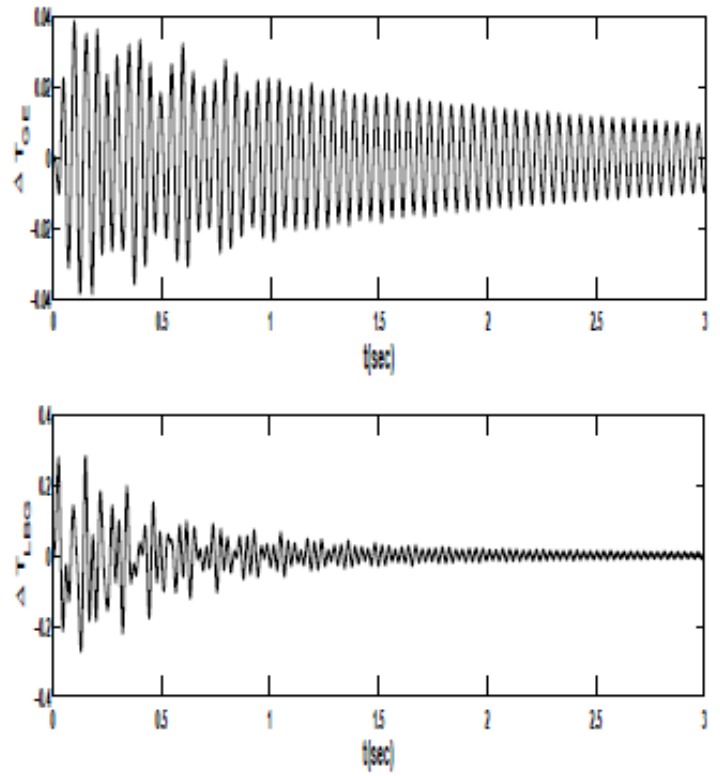

Fig. 16. Variation of $T_{G E}$ and $T_{L B G}$ for $\mathrm{P}=1 \mathrm{pu}, \mathrm{V}=1 \mathrm{pu}, \alpha=165^{\circ}$

The maximum deviation of torque is $0.22 \mathrm{p} . \mathrm{u}$ and it occurs in the shaft section between masses LPA and LPB, as shown in Fig. 17. Within 2 to 3 secs., this deviation reduces to zero. The response of the system for other operating conditions is as shown in Figures?? through??. Figure?? Through 20 corresponds to the operating conditions the real power $\mathrm{P}=0.7 \mathrm{pu}$, terminal voltage $\mathrm{V}=0.9 \mathrm{pu}$, thyristor firing angle $\alpha=$ 1650 and inertia of the mass LPB is reduced to $70 \%$ of its normal value. In the operating conditions real power $\mathrm{P}=.9 \mathrm{pu}$, $\mathrm{V}=1 \mathrm{pu}$, the thyristor firing angle $\alpha=1700$ and if the inertia constant of the mass LPB is increased by $30 \%$ of its normal value, the performance of the system with the proposed controller varies as shown in Figures 21 through 23. When the real power $\mathrm{P}=0.8 \mathrm{pu}$, voltage $=0.8 \mathrm{pu}$ and the thyristor firing angle $\alpha=1700$, the performance of the system varies as shown in Fig 24 through 25
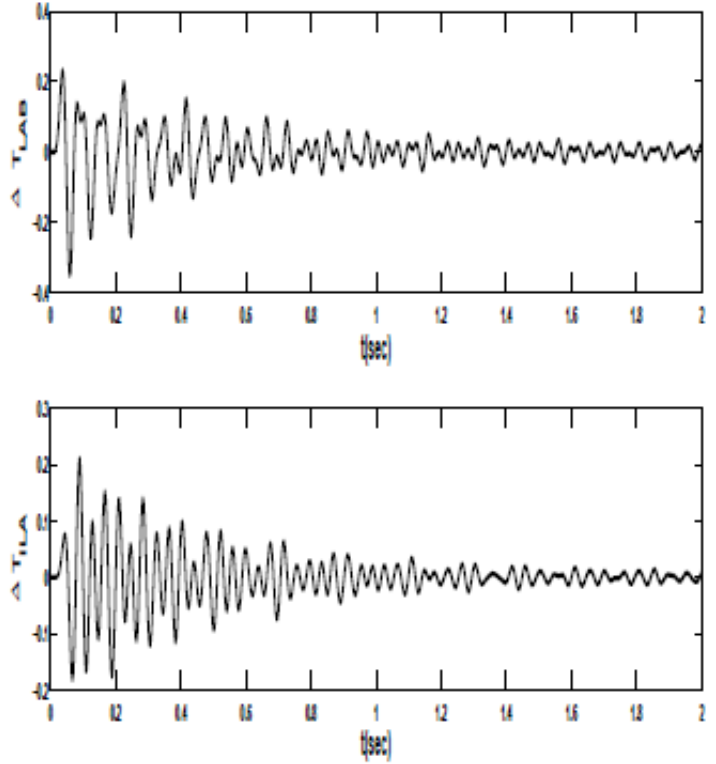

Fig. 17. Variation of $T_{I L A}$ and $T_{L A B}$ for $\mathrm{P}=1 \mathrm{pu}, \mathrm{V}=1 \mathrm{pu}, \alpha=165^{0}$
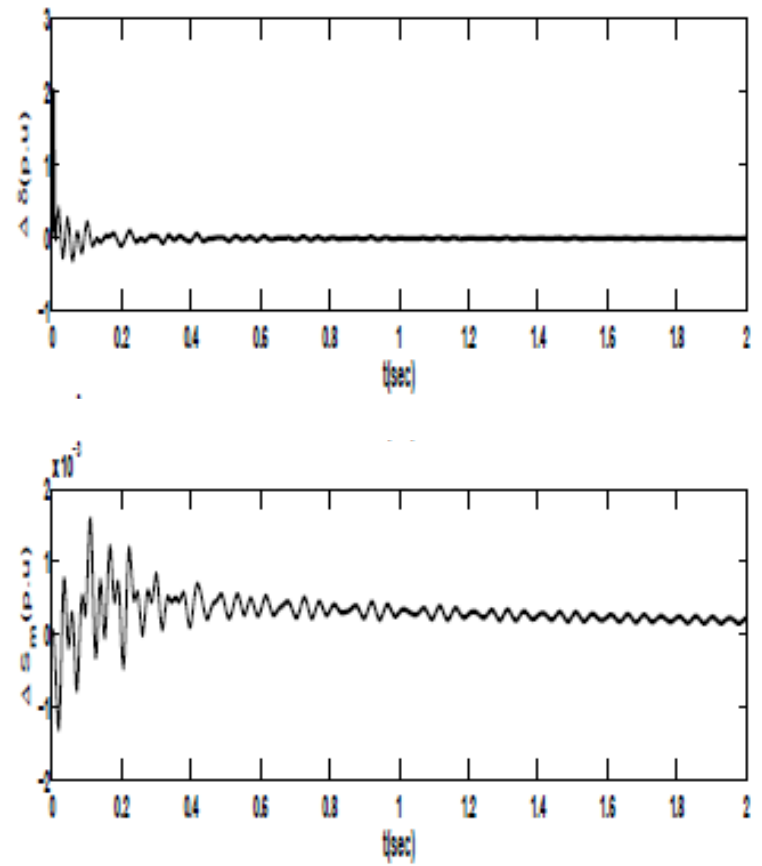

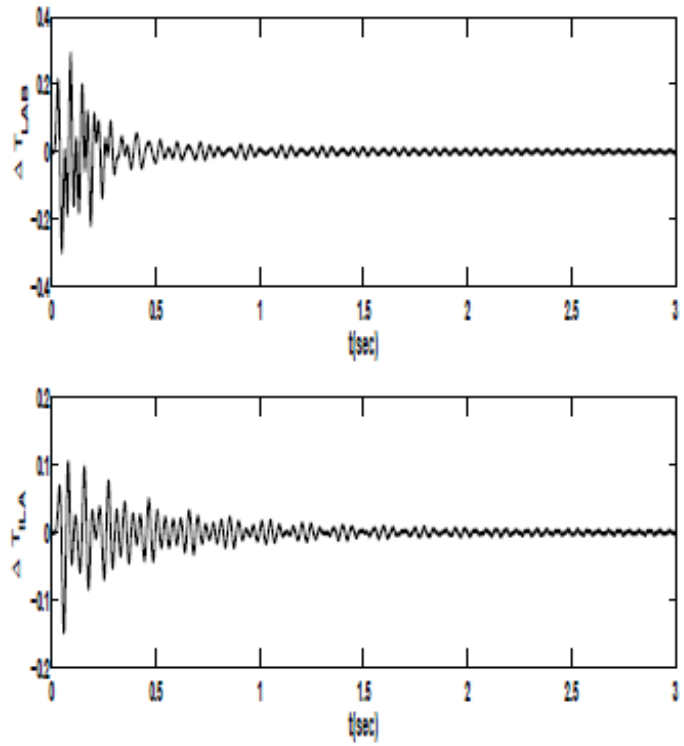

Fig. 19. Variation of $T_{I L A}$ and $T_{L A B}$
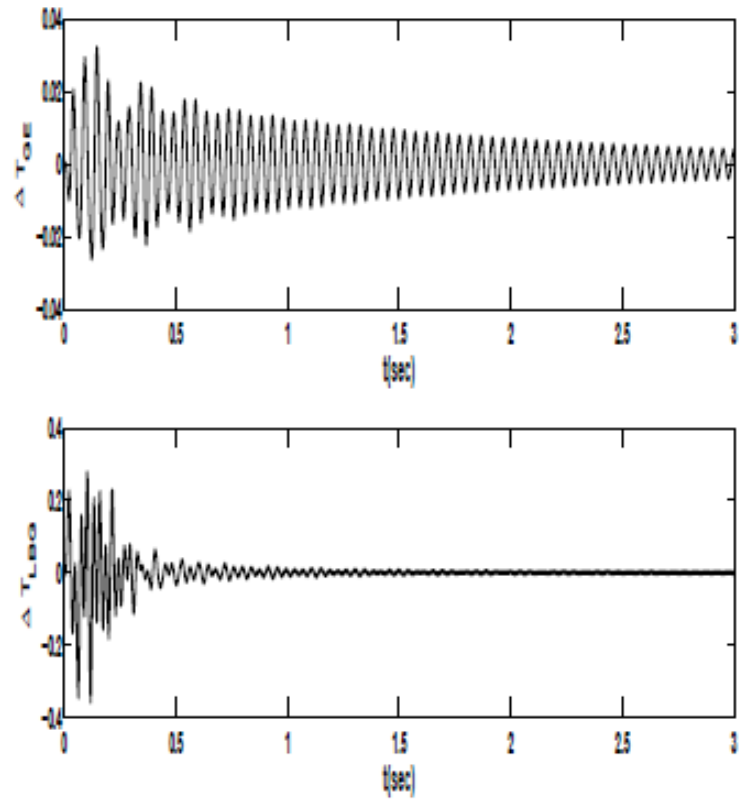

Fig. 20. Variation of $T_{L B G}$ and $T_{G E}$

Similarly, by changing the stiffness of the shaft, the performance of the sysstem with the controller is evaluated for different operating conditions as shown in Fig. 26 through Fig. 31. Figures 26 through 28 corresponds to the operating condition of real power generation of $0.9 \mathrm{pu}$, terminal voltage $\mathrm{V}=1 \mathrm{pu}$ and thyristor firing angle $\alpha=1650$. The stiffness of the shaft section connection between masses IP and LPA is reduced to $80 \%$ of its normal value.
Similarly, for the same operating conditions, when the stiffness of the same shaft section is increased by $20 \%$, the oscillations prolong for more time at the same time, the controller provides damping also as shown in Figs. 29 through 31. It has been observed that the proposd controller give desirable damping of the torsional as well as the swing mode oscillations for all these operating conditions which proves its robustness.
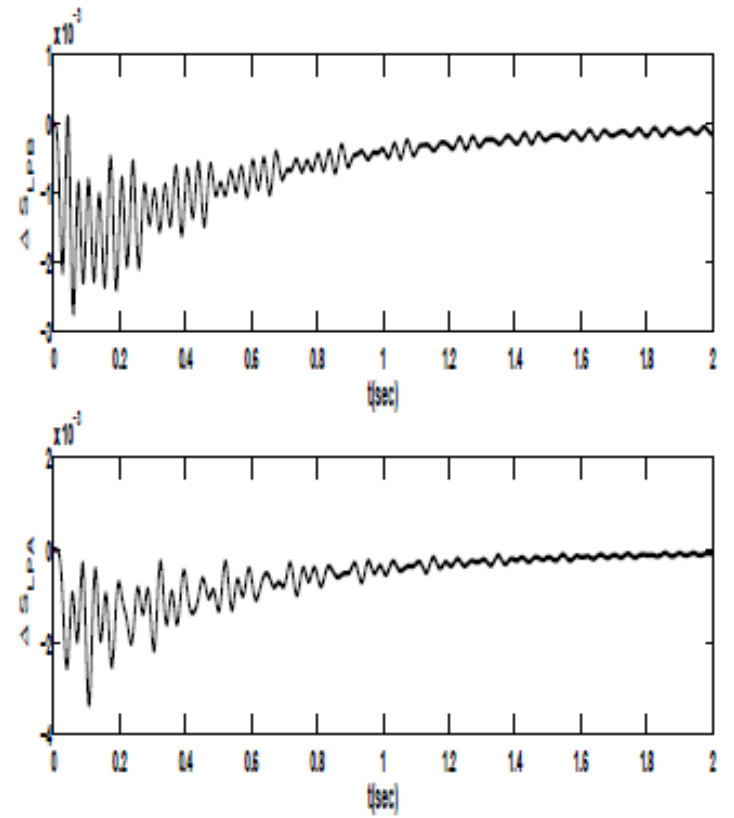

Fig. 21. Variation of $S_{L P_{A}}(\mathrm{pu})$ and $S_{L P B}(\mathrm{pu})$
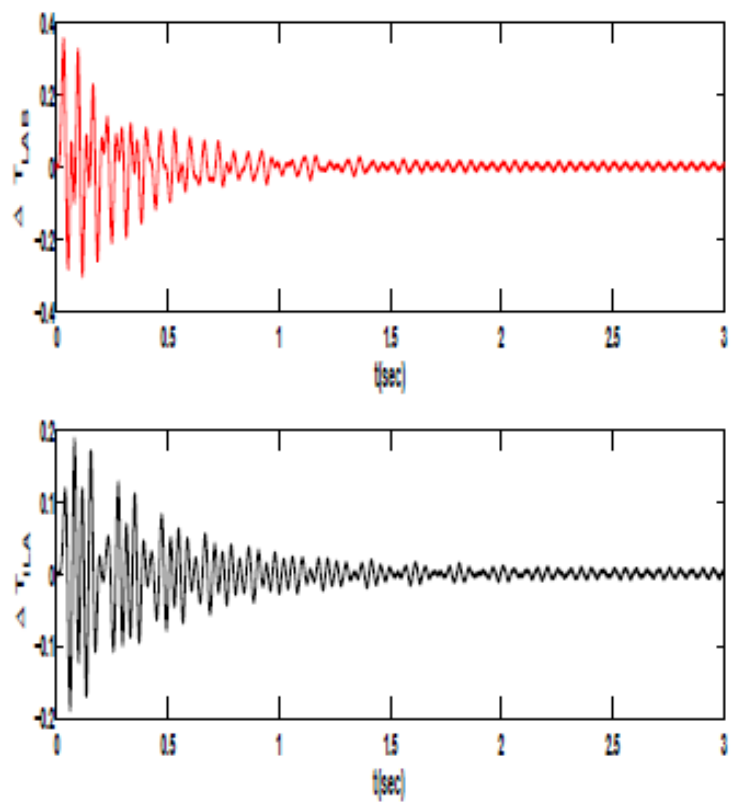

Fig. 22. Variation of $T_{I L A}(\mathrm{pu})$ and $T_{L A B}(\mathrm{pu})$ 
The responses of the system with the reduced DLQG compensator are as shown in Fig. 32. Initially, the DLQG compensator is designed for the system with 27 states, which results in a compensator of order 27. Then, by using Hankel's norm approximation technique, the order of the controller is reduced to 11 [?]. The performance of the system with reduced order DLQG compensator is then compared with the performance of the system obtained with the full order DLQG.

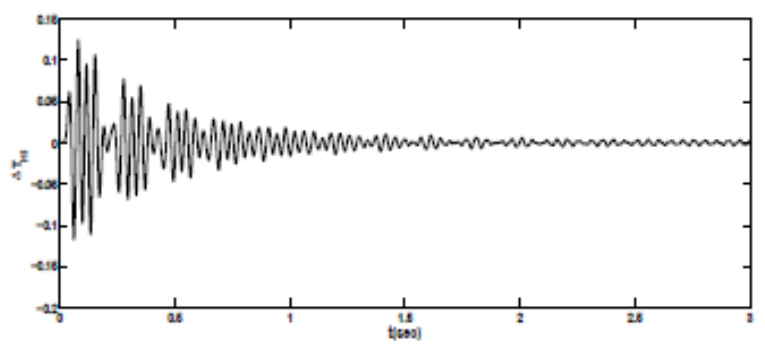

Fig. 23. Variation of $T_{H I}(\mathrm{pu})$
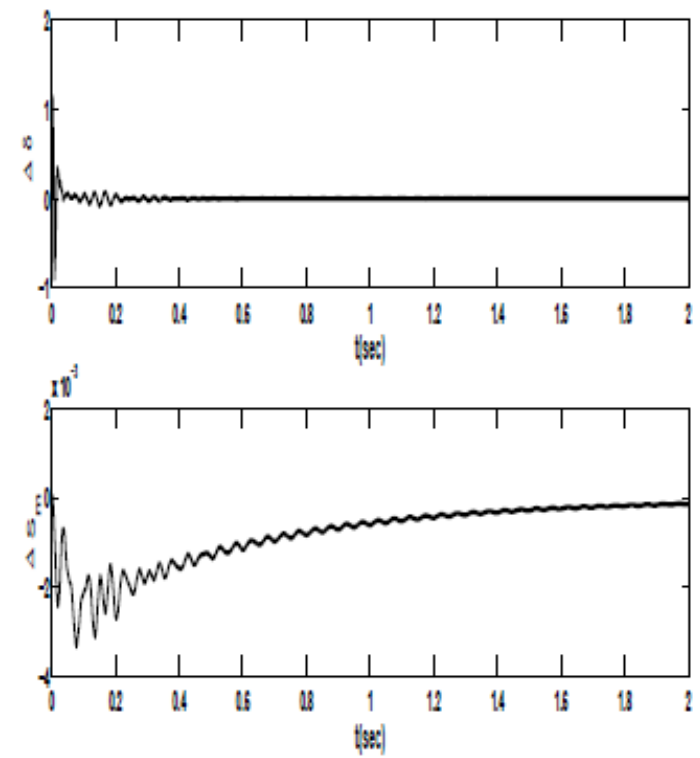

Fig. 24. Variation of Slip(pu) and $\delta(\mathrm{pu})$

It has been observed that the performance of the reduced controller is exactly matching with the full order compensator. In short, the model order reduction techniques can be effectively used to reduce the complexity of implementing the DLQG compensator in large systems without affecting the major system dynamics.

Figures 33 to 35 show the variation of system response with and without the DLQG controller. From these figures, it can be observed that the damping of the torsional modes is improved with the use of DLQG controller.
From these observations, it can be concluded that an effective control of TCSC is possible with DLQG controller. Figures 11, 14 and 15 show the variation of slips in different masses of the mechanical system. Figure 12 and 13 shows the variation of torque in different shaft section. The maximum torque deviation occurs in the shaft section between masses LPA and LPB as shown in Fig.12, but it exists only for a small duration. The simulation results verifies the eigen analysis result. As given in Table 2, even after the major disturbance, the torsional mode 4 is well damped as shown in simulation graphs.
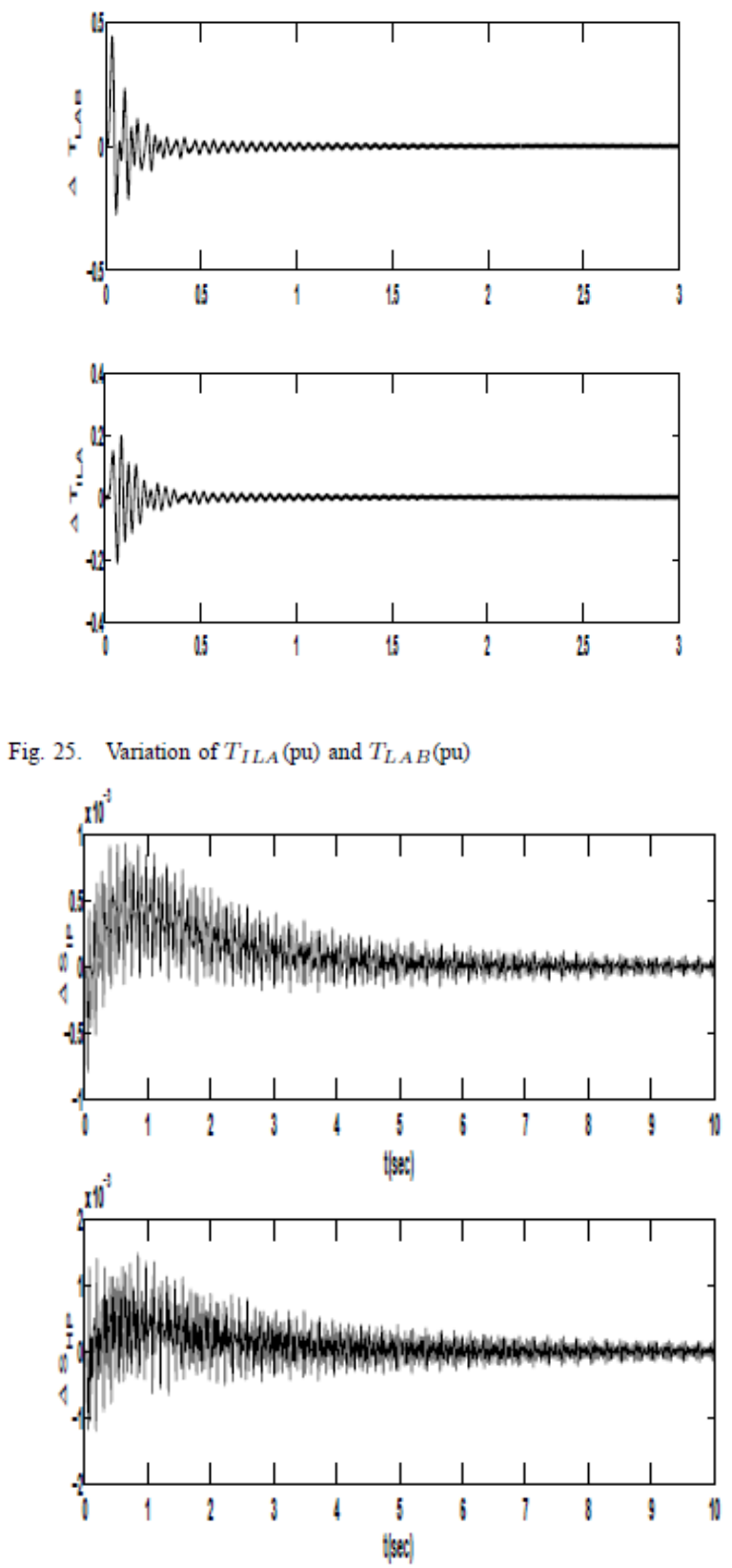

Fig. 26. Variation of $S_{H P}(\mathrm{pu})$ and $S_{I P}(\mathrm{pu})$ 


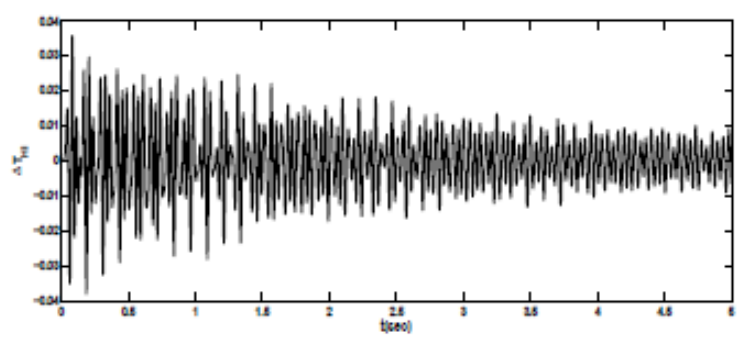

Fig. 27. Variation of $T_{I L A}(\mathrm{pu})$ and $T_{L A B}(\mathrm{pu})$
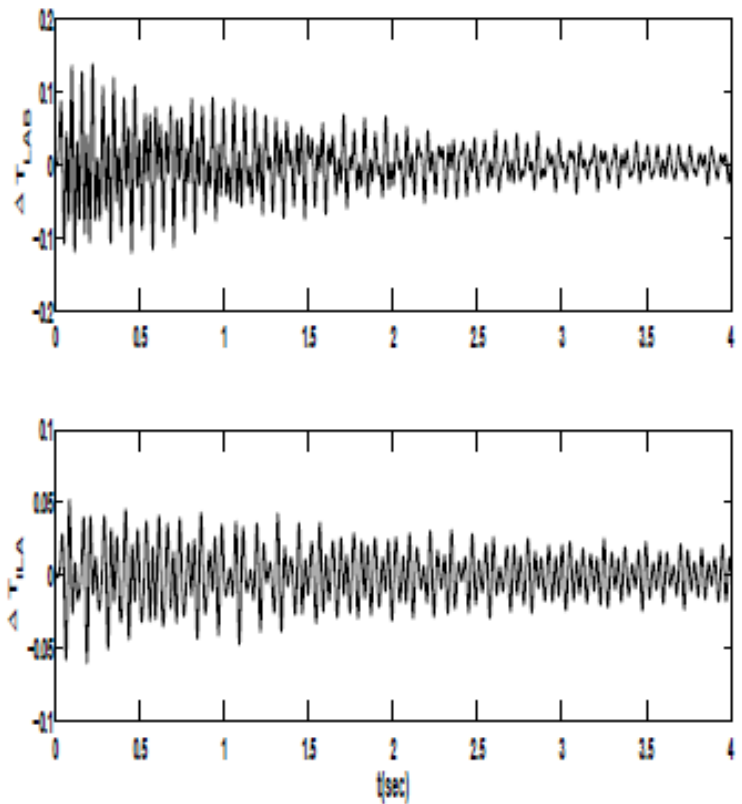

Fig. 28. Variation of $T_{I L A}(\mathrm{pu})$ and $T_{L A B}(\mathrm{pu})$
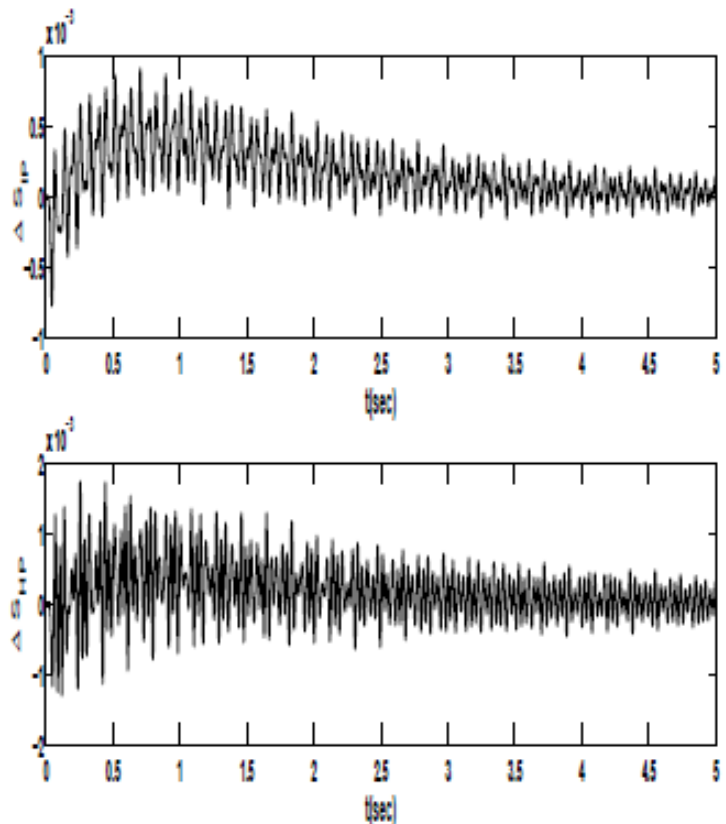

Fig. 29. Variation of Slip(pu)
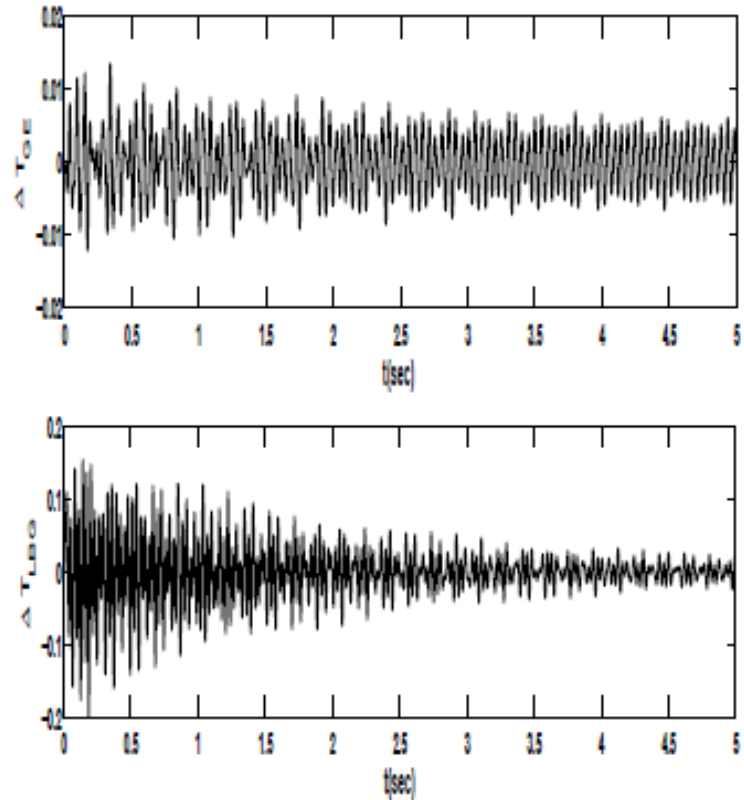

Fig. 30. Variation of $T_{G E}(\mathrm{pu})$ and $T_{L B G}(\mathrm{pu})$ 

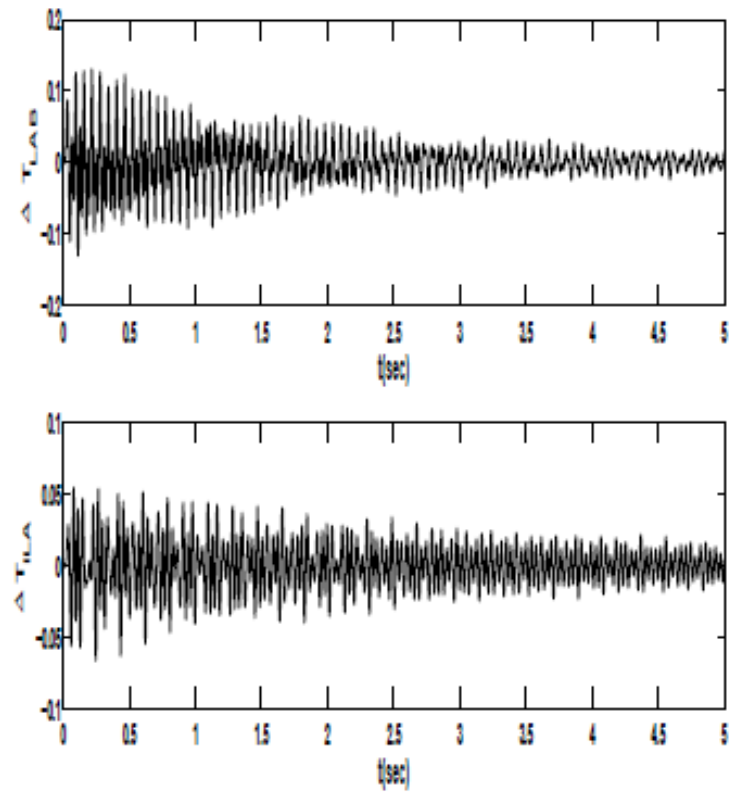

Fig. 31. Variation of $T_{I L A}(\mathrm{pu})$ and $T_{L A B}(\mathrm{pu})$
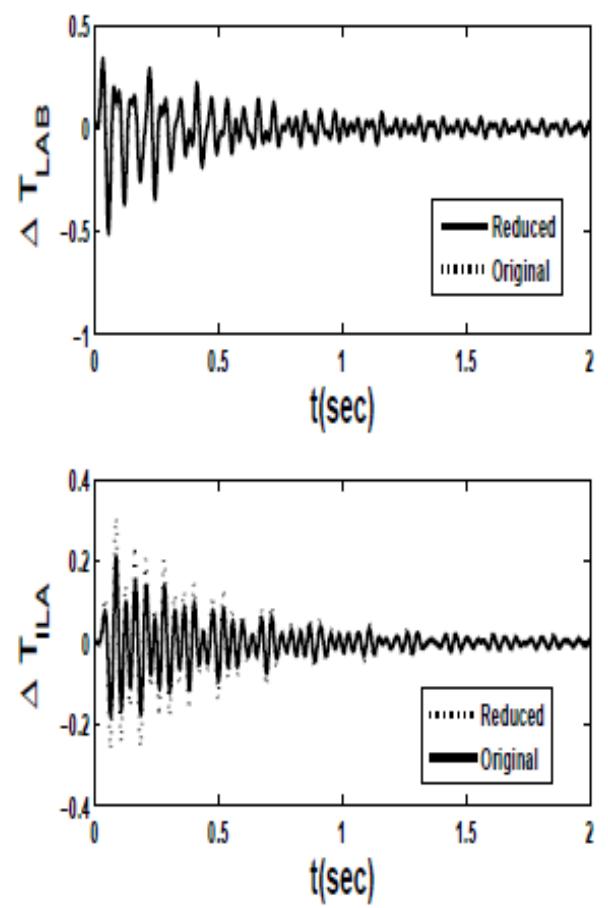

Fig. 32. Comparison of variation of $T_{I L A}$ and $T_{L A B}$ (p.u) with order reduction
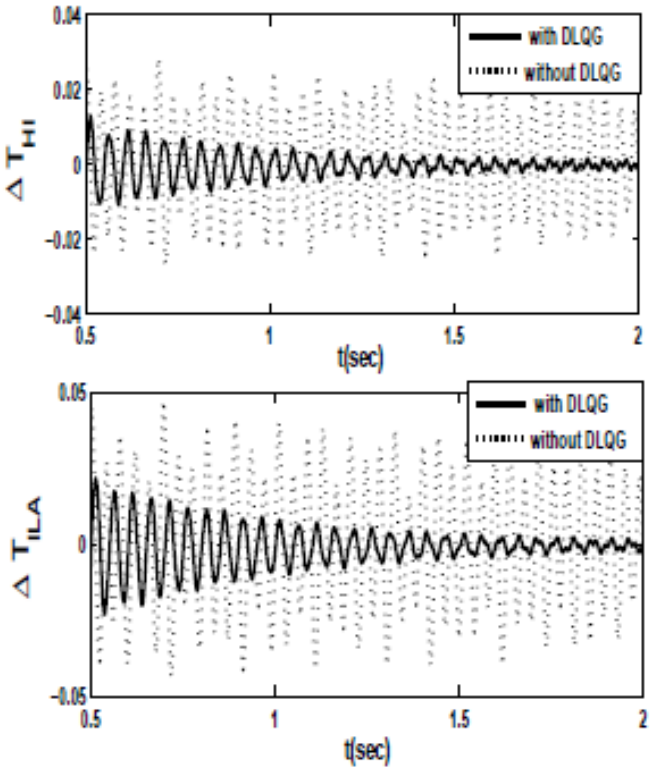

Fig. 33. Response of the system with and without DLQG $\left(T_{H I}\right.$ and $T_{I L A}$ in(p.u))
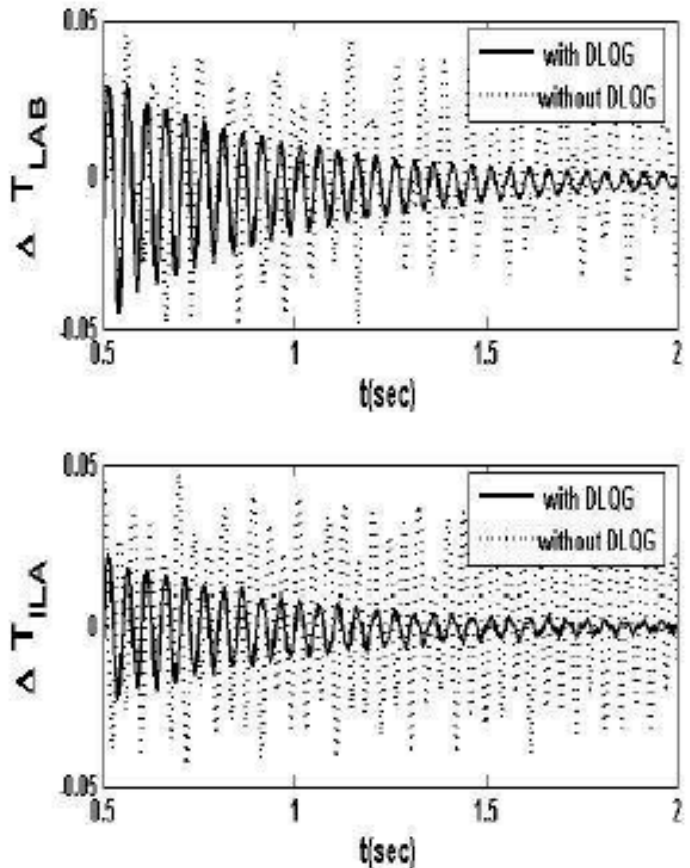

Fig. 34. Response of the system with and without DLQG 

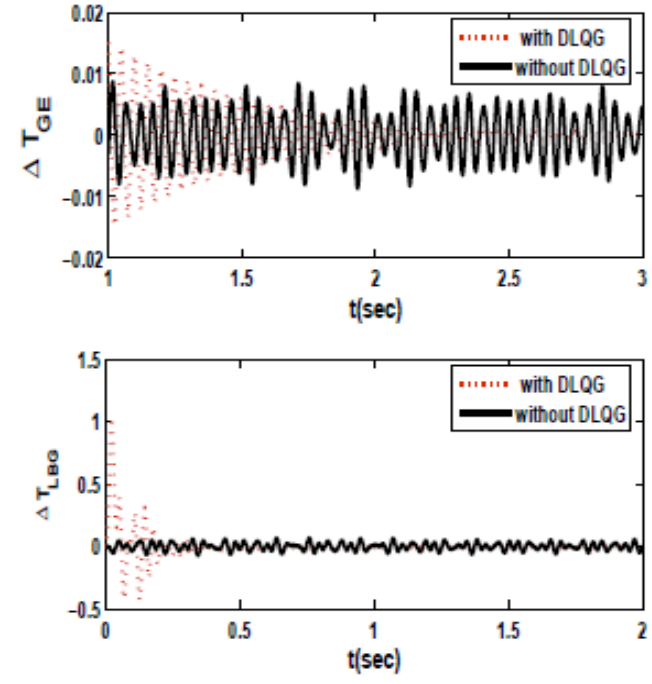

Fig. 35. Response of the system with and without DLQG $\left(T_{G E}\right.$ and $T_{L B G}$ in (p.u))

\section{CONCLUSIONS}

In this paper, the use of a discrete model of TCSC interfaced with the rest of the system in IEEE FBM for SSR analysis and the DLQG compensator design for damping SSR oscillations has been discussed. The design of DLQG involves the design of Kalman estimator for state estimation and state feedback for control law. By conducting eigen analysis on the study system. it is observed that unlike in a conventional controller, the simultaneous damping of swing mode as well as the torsional oscillations are possible with DLQG. Performance of the proposed controller is tested for various operating conditions and proved the robustness of the controller.

\section{REFERENCES}

[1] IEEE Committee Report:" Terms, Definitions and Symbols for Subsynchronous Oscillations", IEEE Trans.Power Apparatus and Systems, vol. PAS-104, pp. 1326-1334, June 1985.

[2] P. M. Anderson, B. L. Agrawal, J. E. Van Ness," Subsynchronous Resonance in Power Systems, "New York: IEEE Press, 1990, pp. 1-269

[3] IEEE Committee Report, "Reader's guide to subsynchronous resonance, IEEE Trans. Power Systems, Vol. 7,No. 1, pp. 150-157, Feb. 1992.

[4] D.N.Walker, C.E Bowler, R.L Jackson and D.A Hodges, "Results of subsynchronous resonance test at Mohave", IEEE Transactions on PAS.pp-1878-1889 Sept/Oct 1975

[5] N.G. Hingorani, "A New Scheme for Subsynchronous Resonance Damping of Torsional Oscillations and Transient Torques- Part 1", IEEE Trans.Power Apparatus and Systems, vol. PAS-100, pp. 1852-1855.1981

[6] D.N. Walker, S.L. Adams, R.J. Placek, "Torsional Vibration and Fatigue of Turbine Generator Shafts", IEEE
Trans. Power Apparatus and Systems vol. PAS-100,No. 11, pp. 4373-4380, Nov. 1981.

[7] E.V.Larsen, J,J, Sanchez-Gasca, J.H.Ghow, "Concepts for design of FACTS controllers to damp power swings," IEEE Trans. Power. Syst. , 1995, No.10, pp.948-956.

[8] G.N.Taranto, J.H Chow, H.A Othman, "Robust redesign of power system damping controller," IEEE Trans. Control Syst. Technol, 1995, No.3, pp.290-298.

[9] B.K.Keshavan, Nagesh Prabhu , "Damping of Subsynchronous oscillations using STATCOM-A FACTS controller," Power System Technology, POWERCON 2004 ,2004,Singapore.

[10] Elizabeth.P.Cheriyan and A.M.Kulkarni,"Discrete Time Dynamic model of NGH Damper,"IEEE Trans. on Power Systems,vol.22, No.4,November 2009.

[11] A.Ghosh, G.Ledwich "Modelling and control of thyristor controlled switched capacitors," Proc. Inst. Elect. Eng, 1995, Vol 142, No.3, pp.297-304.

[12] S.G.Jalali, R.H. Lasseter, I Dobson, "Dynamic response of a thyristor controlled switched capacitors," IEEE Transactions on power delivery, 1994, Vol 9, No.3, pp.1909-1615.

[13] H.A.Othman and L.Angquist,"Analytical modelling of Thyristor controlled series capacitor for SSR study ," IEEE Transactions on power system, 1996, Vol 11, No.1, pp.119127.

[14] K. Kabiri,S.Henshel, J.R.Marti, H.W.Dommel, "A Discrete state space model for SSR stabilising controller design for TCSC compensated system," IEEE Transactions on power delivery, 2005, Vol 20, No.1, pp.466-473.

[15] S.R.Joshi,A.M.Kulkarni "Analysis of SSR performance of TCSC control schemes using a Modular High Bandwidth Discrete-Time Dynamic model," IEEE Transactions on power system,2009, Vol.24, No.2, May 2009, pp.840-848

[16] Y.N.Yu, Electric power system Dynamics, Academic Press 1983.

[17] G.N.Taranto, J.H Chow "A Robust frequency domain optimisation technique for tuning series compensation damping controllers,"IEEE Transactions on power system, 1995, Vol 10 , No.3, pp.1219-1225.

[18] G.N.Pillai, Arindam Ghosh, A.Joshi "Robust control of SSSC to improve Torsional Damping," 2001, pp.1115-1120.

[19] Gunter Stein,Michael Athans "The LQG/LTR Procedure for Multivariable feedback control design," IEEE Transactions on Automatic Control, 1987, Vol 32, No.2, pp.105-114.

[20] Jang-Cheol Seo,Jong Keun Park "An LQG based PSS design for controlling SSR in power systems with series compensated lines," IEEE Transactions on Energy Conversion , 1996, Vol 11, No.1, pp.423-428.

[21] K.Ramesh, A.N.Nirmal Kumar,G.Gurusamy "Design of Discrete controller via a Novel Model order reduction Technique,"International Journal of Electrical and Power Engineering,2009, Vol 3, pp.163-168.

[22] Chen C.F "Model Reduction of multivariable control systems by means of matrix continued fraction," International journal of control

$[23]$ " $\mu$ analysis and synthesis toolbox". 